\title{
Modelling the reversible uptake of chemical species in the gas phase by ice particles formed in a convective cloud
}

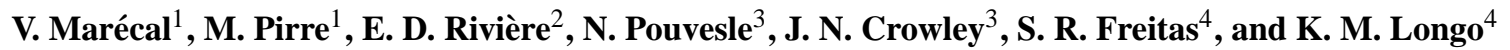 \\ ${ }^{1}$ Laboratoire de Physique et Chimie de l'Environnement et de l'Espace, CNRS-Université d'Orléans, UMR6115, \\ Orléans, France \\ ${ }^{2}$ Groupe de Spectrométrie Moléculaire et Atmosphérique, Université de Reims-CNRS, Reims, France \\ ${ }^{3}$ Max-Planck-Institut für Chemie, Division of Atmospheric Chemistry, Mainz, Germany \\ ${ }^{4}$ Center for Weather Forecasts and Climate Studies, INPE, Cachoeira Paulista, Brazil
}

Received: 22 October 2009 - Published in Atmos. Chem. Phys. Discuss.: 16 November 2009

Revised: 26 April 2010 - Accepted: 18 May 2010 - Published: 31 May 2010

\begin{abstract}
The present paper is a preliminary study preparing the introduction of reversible trace gas uptake by ice particles into a 3-D cloud resolving model. For this a 3-D simulation of a tropical deep convection cloud was run with the BRAMS cloud resolving model using a two-moment bulk microphysical parameterization. Trajectories within the convective clouds were computed from these simulation outputs along which the variations of the pristine ice, snow and aggregate mixing ratios and concentrations were extracted. The reversible uptake of 11 trace gases by ice was examined assuming applicability of Langmuir isotherms using recently evaluated (IUPAC) laboratory data. The results show that ice uptake is only significant for $\mathrm{HNO}_{3}, \mathrm{HCl}, \mathrm{CH}_{3} \mathrm{COOH}$ and $\mathrm{HCOOH}$. For $\mathrm{H}_{2} \mathrm{O}_{2}$, using new results for the partition coefficient results in significant partitioning to the ice phase for this trace gas also. It was also shown that the uptake is largely dependent on the temperature for some species. The adsorption saturation at the ice surface for large gas mixing ratios is generally not a limiting factor except for $\mathrm{HNO}_{3}$ and $\mathrm{HCl}$ for gas mixing ratio greater than $1 \mathrm{ppbv}$. For $\mathrm{HNO}_{3}$, results were also obtained using a trapping theory, resulting in a similar order of magnitude of uptake, although the two approaches are based on different assumptions. The results were compared to those obtained using a BRAMS cloud simulation based on a single-moment microphysical scheme instead of the two moment scheme. We found similar results with a slightly more important uptake when using the singlemoment scheme which is related to slightly higher ice mixing ratios in this simulation. The way to introduce these results in the 3-D cloud model is discussed.
\end{abstract}

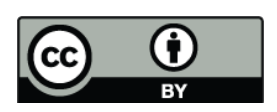

Correspondence to: V. Marécal (virginie.marecal@cnrs-orleans.fr)

\section{Introduction}

It is well known that deep convective clouds transport chemical species rapidly from the lower troposphere to the upper troposphere (e.g. Dickerson et al., 1987; Wang et al., 1995; Marécal et al., 2006; Rivière et al., 2006) and occasionally directly to the lower stratosphere (e.g. Danielsen, 1993; Fischer et al., 2003). Convective transport is particularly important in the tropics where deep convection is frequent. Rain formed in the convective clouds also plays an important role in the perturbation of the chemical composition of the troposphere by washing out soluble species and also by reactions of the soluble species within the liquid phase (see review work by Warneck, 2000). Deep convective clouds also contain large amounts of ice crystals that can interact with the gas species in the air. The processes associated with the liquid phase can act up to altitude levels corresponding to about $235 \mathrm{~K}$ together with ice phase. At ambient temperatures below $235 \mathrm{~K}$, the ice phase processes are dominant.

Tropospheric chemistry models generally take into account the transport, the chemical transformation of the gas species and the interactions of these species with liquid droplets (e.g. Mari et al., 2000; Barth et al., 2000). The equilibrium between the gas phase and the liquid phase is given by the effective Henry's constant (Sander, 1999) and is not reached for all species on each model time step. For these species the evolution of the mixing ratio of the gas and the liquid species towards this equilibrium can be computed (Audiffren et al., 1998; Barth et al., 2001). Most models also take into account the chemical reactions in the liquid phase.

In contrast, the interaction of the gas species with ice particles is either not incorporated in models or, due to the complexity of the processes involved, is taken into account using simplified approaches. In nature some of the atmospheric

Published by Copernicus Publications on behalf of the European Geosciences Union. 
ice crystals are dry, pure ice particles but others are mixed with liquid water or doped with gas species at their surface or even formed with composite crystals (Nitric Acid Trihydrate in polar stratospheric clouds for example). Their surface has a variety of geometric forms (e.g. needles, hexagonal plates, columns), some of them being complex (dendrites, aggregates). The different kinds and properties of real atmospheric ice particles are difficult to reproduce in laboratory studies. The interaction of the gas species with ice can be reactive or reversible or a mixture of both. Finally, the chemical species dissolved in the liquid droplets may be partially or totally retained when droplets freeze by riming or through the activation of ice nuclei, or may be released to the gas phase. Because of this complexity, all these processes are generally not taken into account in tropospheric chemistry models, though a few have attempted to include a representation of some of these processes. Tabazadeh and Turco (1993) developed a surface chemistry model to describe the heterogeneous chemical processes on ice surfaces relevant to polar stratospheric clouds. In this model the nonreactive adsorption of $\mathrm{HNO}_{3}$ and $\mathrm{HCl}$ was described by the Langmuir isotherm in terms of the equilibrium surface coverage for a non-dissociative adsorption. The reactive interaction of stratospheric trace gases with ice surfaces was described by a first-order uptake coefficient. Using the same surface chemistry model, Tabazadeh et al. (1999) described the nonreactive adsorption of $\mathrm{HNO}_{3}$ on cirrus clouds by the Langmuir isotherm assuming a dissociative adsorption. Meier and Hendricks (2002) performed sensitivity studies of the influence of uptake of $\mathrm{HNO}_{3}$ by cirrus clouds on tropospheric chemistry. They used the formulation of Tabazadeh and Turco (1993) incorporating the laboratory data of Abbatt (1997) and Zondlo et al. (1997) for the nonreactive interaction of $\mathrm{HNO}_{3}$ with ice surfaces. Nonreactive adsorption of $\mathrm{H}_{2} \mathrm{O}_{2}$ was optionally included. They also considered the uptake of adsorbed trace gases into the bulk of the ice crystal when the particle size distribution is changing due, for instance, to aggregation of ice crystals. They showed that these processes lead to a large decrease of $\mathrm{NO}_{\mathrm{x}}$ and therefore to a reduction in ozone production. Using a three-dimensional cloud resolving model with interactive dynamics, aerosols, cloud microphysics, radiation and chemistry, Wang (2005) calculated the uptake of several key species based on first order uptake coefficients by ice particles formed in a tropical deep convective event. The simulations showed large concentrations of ozone and formaldehyde in the ice phase. $\mathrm{HNO}_{3}$ in the ice phase is only located at the edge of the convective turrets. The author is aware nevertheless of possible large uncertainties on these results due to the very approximate uptake coefficients used (i.e. ignoring surface equilibrium by considering only accommodation). Nitric acid uptake by ice was also examined in the MATCH-MPIC Chemistry Transport Model (von Kuhlmann and Lawrence, 2006) in which different parameterisations of uptake were compared, including dissociative Langmuir uptake with different adsorption enthalpies and a description of the uptake analogous to the Henry's law allowing bulk uptake (Crutzen and Lawrence, 2000; von Kuhlmann et al., 2003). Several studies (Mari et al., 2000; Barth et al., 2001; Yin et al., 2002) also showed that when liquid droplets freeze during riming, the retention coefficient plays an important role for the transport of chemical species from the lower troposphere to the upper troposphere in convective clouds. Within the convective updraft, species of low solubility are transported by air and can interact with ice particles in the upper troposphere while soluble species only reach the upper levels if degassed when droplets are freezing (retention coefficient close to 0 ) during riming. Yin et al. (2002) defined an additional parameter called the gas burial efficiency which is the amount of trace gases trapped within the ice particles. They showed that the transport of the gas species from the lower troposphere to the upper troposphere is not very sensitive to this burial efficiency because of the ice sedimentation.

In this context, the ultimate objective of this work is to include the removal of various chemical species from the gas phase by ice particles in a three-dimensional cloud resolving model for studying its impact on air composition in tropical deep convective environments. Here we present a preliminary study to assess the importance of the ice uptake process for various trace gases in the cold part of a deep convective cloud (temperature lower than $235 \mathrm{~K}$ ) in order to prepare its parameterisation in the 3-D model.

In the cold part of a convective cloud, the trace gases which interact with the ice particles are:

1. low solubility species which are not efficiently scavenged by liquid droplets,

2. any trace gas in air parcels of the environment entrained in the convective updraft at the ice formation level

3. trace gases initially in air parcels located at high altitude and experiencing ice formation because of the waves generated by the convective event.

In the first stage, we limit our work to the simulation of reversible uptake of gas species by dry pure ice particles. Two different approaches have been proposed in the literature to describe this process. The first one is the Langmuir approach which assumes equilibrium between the gas phase concentration and the number (per $\mathrm{cm}^{2}$ of ice) of surface adsorbed molecules. This equilibrium can be derived from the surface partition coefficient $K_{\text {linC }}$ and the maximum number of sites available for adsorption $N_{\mathrm{MAX}}$. A large number of laboratory studies (Abbatt, 1997; Chu et al., 2000; Bartels et al., 2002; Dominé and Rey-Hanot, 2002; Hudson et al., 2002; Hynes et al., 2002; Sokolov and Abbatt, 2002; Winkler et al, 2002; Bartels-Rausch et al., 2004; Peybernès et al., 2004; Cox et al., 2005; Ullerstam and Abbatt; 2005; Kerbrat et al., 2007; von Hessberg et al., 2008) have been recently assessed by the IUPAC Subcommittee on 
Gas Kinetic Data Evaluation (see Crowley et al., 2010 and http://www.iupac-kinetic.ch.cam.ac.uk) to derive the partition coefficients for several species of atmospheric interest. In these simulations made for low temperature $(<250 \mathrm{~K})$, the thermodynamic state of the ice surface (solid, quasi-liquid or disordered surface layers) is not considered. Whilst recognising that the ice-gas interface is very dynamic, with $100 \mathrm{~s}$ of monolayers of water adsorbing and desorbing every second even at cirrus cloud temperatures, laboratory work has shown that Langmir isotherms are able to adequately describe the gas-ice partitioning. The second approach has been proposed by Diehl at al. (1995), Clegg and Abbatt (2001), Kärcher and Basko (2004), Huffman and Snider (2004), Ullerstam and Abbatt (2005), Voigt et al. (2007) who suggest that the Langmuir approach is not valid in a real environment where the ice particles are generally not found in equilibrium conditions during cloud lifetime. Kärcher and Basko (2004) developed a theory of trapping of trace gases when ice particles grow by water deposition at temperatures below $240 \mathrm{~K}$. Recently, Kärcher et al. (2009) extended this theory and applied it to $\mathrm{HNO}_{3}$ using laboratory and field campaign data. In trapping theory the Langmuir approach is assumed to be valid only when the ice particle size remains constant. When ice is growing by water deposition, trace gases can be trapped into the bulk of the ice particles and are released to the gas phase only when the ice particles evaporate. The inclusion of several oxygenates in growing ice films has been investigated experimentally by Huffman and Snider (2004). Their results (obtained at ice temperatures between -4 and $-24^{\circ} \mathrm{C}$ ) suggest a positive dependence of the derived volume uptake coefficient on temperature and no dependence on ice growth rates, which contrasts the Kärcher et al. (2009) trapping mechanism. Their data suggests that the volume uptake of certain organics in growing ice crystals at warm ice temperatures is more important than surface uptake under comparable conditions However, since the data presented by Huffman and Snider (2004) do not cover the relevant temperature range for the present study and it is unclear whether the positive temperature dependence can be extrapolated to lower temperatures, we do not consider their parameterisation. Here we present results on the ice uptake process based on both the Langmuir and the Kärcher et al. (2009) trapping approaches. For the Langmuir approach the uptake efficiency for 11 different species is treated. For the trapping approach, only $\mathrm{HNO}_{3}$ is studied since the necessary parameters are only available for this species at temperatures below $235 \mathrm{~K}$.

In order to take into account realistic ice mixtures, the uptake calculations are made along air parcel trajectories within an idealized convective cloud simulated with the 3-D mesoscale model BRAMS. Accurate calculation of the evolution of trace gas mixing ratios along these trajectories is out of the scope of this paper; at each point of the trajectories, parameters are computed to assess the importance of the ice uptake. These parameters are instantaneous values which do not depend on the history along the trajectories.

The descriptions of the BRAMS model, of the idealized simulation of a deep tropical convective cloud and the air parcel trajectory results are given in Sect. 2. Section 3 is devoted to the results of the Langmuir approach. The trapping results for $\mathrm{HNO}_{3}$ are provided in Sect. 4. In Sect. 5 the impact of one particular ice category (graupel) in the Langmuir and the trapping approaches is discussed. In Sect. 6 we compare the results of the two approaches and their implications for their use in a 3-D coupled meteorology-chemistry cloud resolving models.

\section{Convective cloud simulation}

\subsection{Model description}

The BRAMS model (Brazilian developments on the Regional Atmospheric Modeling System, http://www.cptec. inpe.br/brams) is used in the present study to simulate an idealized deep convective cloud developing in a tropical environment. BRAMS is a version of the RAMS (Walko et al., 1995) tailored to the tropics, the main features of BRAMS are described in Freitas et al. (2009) . The BRAMS/RAMS model is a multipurpose numerical prediction model designed to simulate atmospheric circulations spanning in scale from hemispheric scales down to large eddy simulations of the planetary boundary layer.

Two cloud microphysical schemes based on a bulk approach have been used. They both include rain, liquid cloud and five categories of ice: pristine ice, snow, aggregates, graupel and hail. They also assume a generalised gamma size distribution for each category of hydrometeors. Using this formalism leads for any category to :

$n(D)=\frac{N_{t}}{\Gamma(v)}\left(\frac{D}{D_{n}}\right)^{\nu-1} \frac{1}{D_{n}} \exp \left(-\frac{D}{D_{n}}\right)$

and

$q=\frac{1}{\rho_{a}} \int_{0}^{\infty} n(D) m(D) d D=\frac{N_{t}}{\rho_{a}} \alpha_{m} D_{n}^{\beta_{m}} \frac{\Gamma\left(v+\beta_{m}\right)}{\Gamma(v)}$

where $n(D)$ is the number density distribution $\left(\mathrm{m}^{-4}\right), D$ is the diameter of an equivalent spherical particle having the same volume as the actual particle $(m), N_{t}$ the total concentration $\left(\mathrm{m}^{-3}\right), v$ is the shape parameter and $D_{n}$ the characteristic diameter of the number density distribution, $\Gamma$ is the gamma function, $q\left(\mathrm{~kg} \mathrm{~kg}^{-1}\right)$ is the mixing ratio, $m(D)$ is the mass of an ice particle of diameter $D, \rho_{a}$ is the air density $(\mathrm{kg}$ $\mathrm{m}^{-3}$ ) and $\alpha_{m}$ and $\beta_{m}$ are the coefficient of the mass-diameter relationship for the considered hydrometeor category:

$m(D)=\alpha_{m} D^{\beta_{m}}$

with $m(D)$ the mass in $\mathrm{kg}$ and $\alpha_{m}$ in $\mathrm{kg} \mathrm{m}^{-\beta_{m}}$. 
The crystal shape assumed in the microphysical processes for the pristine ice and the snow is diagnosed at each grid point depending on temperature and relative humidity. In nature, the crystal shape depends on its history but it would be very complex in the bulk microphysical scheme used, which describes the hydrometeor size distribution with an analytical function, to keep this history which depends on the cristal size.

The first microphysical scheme used is the two-moment bulk scheme described in Meyers et al. (1997). It includes prognostic equations for both the mixing ratio and total concentration for total water, rain and the five categories of ice. In this case, only one of the three parameters of the gamma distribution needs to be set (either $v, D_{n}$ or $N_{t}$ ). In all this work the shape parameter $v$ is set to $v=2$. The second microphysical scheme is the single-moment bulk scheme described in Walko et al. (1995) which includes prognostic equations for the mixing ratios of total water, rain and all five ice categories, and a prognostic equation for the total concentration of pristine ice. This implies that, except for pristine ice, two parameters of the gamma distribution are set and do not vary during the simulation. In both microphysical schemes the water vapour and liquid cloud mixing ratios are diagnosed from the prognostic variables by calculating the difference between the total water mixing ratio and the total hydrometeor (ice+rain) mixing ratio. Then water vapour and liquid cloud can be derived from this quantity assuming that water vapour cannot be higher than saturation and that liquid cloud is only formed when saturation is reached.

In the model, pristine ice is formed by nucleation and can only grow by vapour deposition (Walko et al., 1995). The pristine ice category is restricted to relatively small crystals and large pristine ice crystals are categorized as snow. The snow category is defined as consisting of relatively large ice crystals which have grown by vapour deposition and riming. Aggregates are defined as ice particles that have formed by collision and coalescence of pristine ice, snow and/or other aggregates. Pristine ice, snow and aggregates are all low density and low fall-speed particles. Graupel is an intermediate density hydrometeor with an assumed spherical shape formed by moderate to heavy riming and/or partial melting of pristine ice, snow and aggregates. Hail is a high-density hydrometeor with an assumed spherical shape formed by freezing of raindrops or by riming or by partial melting of graupel. Note that the definition of the snow and aggregates categories in the BRAMS model may be different from other models in which the graupel category could be similar to the BRAMS snow category and the snow category could be similar to the BRAMS aggregates category.

\subsection{Model setup}

Two simulations of an idealized tropical convection cloud based on the same general setup were run with the BRAMS model: a reference simulation (REF) using the two-moment bulk microphysical scheme and a sensitivity test (RUN1M) using the single-moment. By using two prognostic equations per hydrometeor category, the two-moment scheme provides a better description of the ice microphysics. A sensitivity simulation was run using the single-moment scheme to evaluate the impact of the microphysical scheme chosen on ice uptake. The shape parameter $v$ is set to 2 for all hydrometeor categories in REF and RUN1M simulations. For RUN1M, the characteristic diameter $D_{n}$ is set to $0.173 \mathrm{~mm}$ for rain, $0.064 \mathrm{~mm}$ for snow, $0.190 \mathrm{~mm}$ for aggregates, $0.346 \mathrm{~mm}$ for graupel and $0.520 \mathrm{~mm}$ for hail while the total concentration $N_{t}$ is set to $7.5 \times 10^{7}$ particles $\mathrm{m}^{-3}$ for liquid cloud. These values were chosen because they correspond to approximately the mean values provided by the two-moment simulation (REF).

In both simulations the parameterization used for longwave/shortwave radiation is from Harrington (1997). It is a two-stream scheme which interacts with liquid and ice hydrometeor size spectra. The turbulence parameterization is from the Mellor and Yamada (1982) level 2.5 scheme which employs a prognostic turbulent kinetic energy.

The domain is $120 \mathrm{~km} \times 120 \mathrm{~km}$ with a $1 \mathrm{~km}$ horizontal grid spacing. It extends vertically from the surface to $25 \mathrm{~km}$ altitude with a $200 \mathrm{~m}$ grid spacing up $18 \mathrm{~km}$ and coarser above. The time-step is $2 \mathrm{~s}$. To simulate an idealized tropical convective cloud we used temperature, pressure, horizontal wind and humidity data from a typical tropical radiosounding during the wet season not showing any peculiar feature. Here we chose a radiosounding launched from Bauru (Brazil, $22.4^{\circ} \mathrm{S}, 49.0^{\circ} \mathrm{W}$ ) on the 3 February 2004 at 18:00 UT in the frame of the TroCCiBras project (Tropical Convection and Cirrus experiment Brazil, Held et al., 2008). These meteorological quantities are assumed to be horizontally homogeneous at the beginning of the simulation. A warm and moist perturbation is applied during the first $750 \mathrm{~s}$ of the simulation below $1 \mathrm{~km}$ altitude and over a horizontal area having a $15 \mathrm{~km}$ diameter. This perturbation is located in the South West part of the domain. This leads to an unstable atmosphere and creates a convective cloud, which reaches the tropical upper troposphere and forms liquid and ice hydrometeors. This type of initialisation (warm and moist perturbation) is often used to model convection and was in particular used by Grosvenor et al. (2007) in a large eddy simulation model to simulate overshooting convection observed near Bauru on 24 February 2004.

\subsection{Results of the cloud simulations}

The results of the REF simulation for pristine ice, snow and aggregate mixing ratios are displayed in Fig. 1. Graupel and hail categories are not shown since they are assumed in the BRAMS model to carry also liquid water. Therefore they are not considered for ice uptake calculations. The sum of pristine ice, snow and aggregates will be called "dry ice" in 

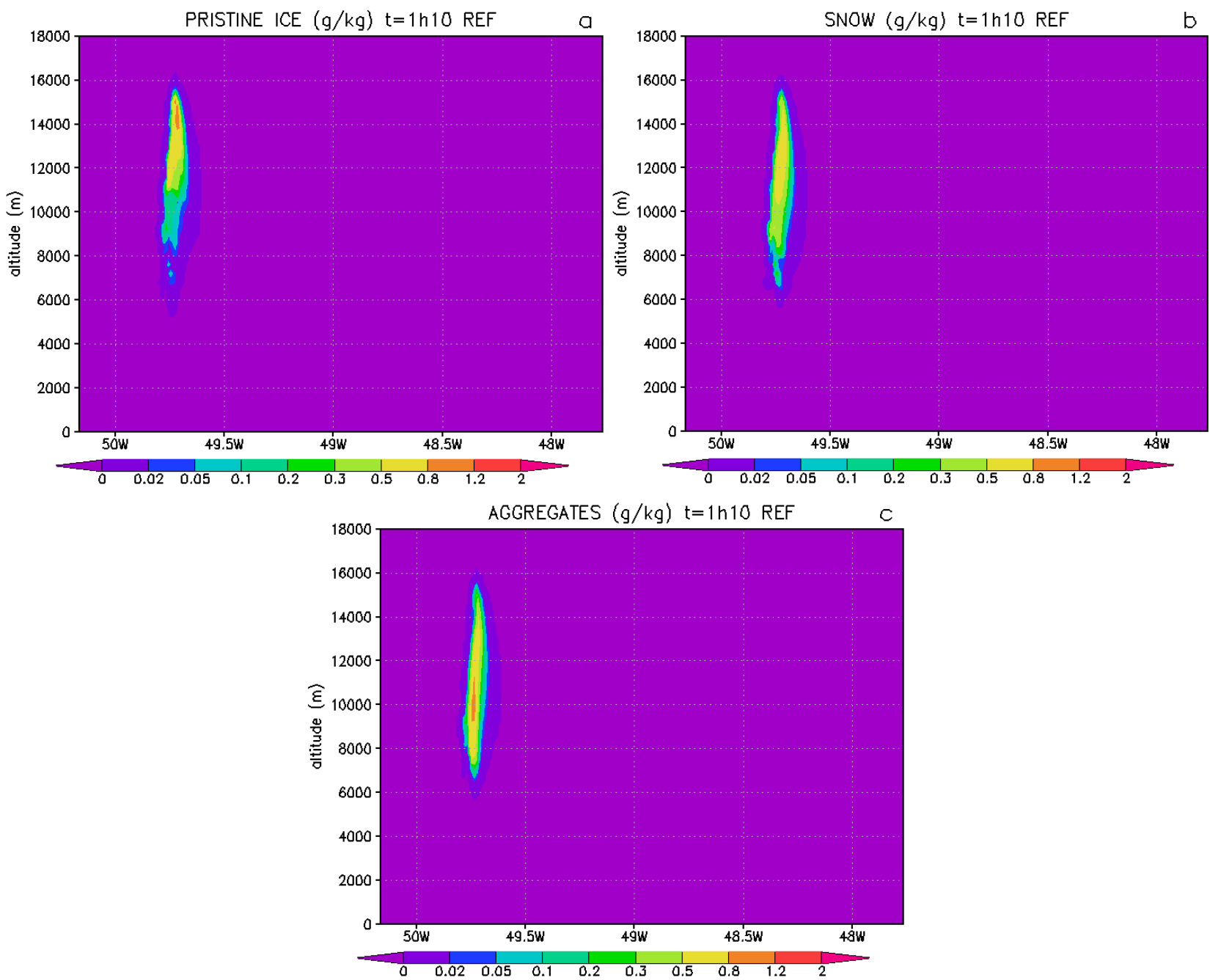

Fig. 1. Vertical cross-sections from surface to $18 \mathrm{~km}$ height within the convective cloud from the REF simulation. Panels (a, d, g), panels (b, $\mathbf{e}, \mathbf{h})$ and panels (c, f, i) correspond respectively to the mixing ratio of pristine ice, of snow. and of aggregates. Panels (a, b, c), panels (d, e, f) and panels (g, h, i) are respectively for 01:10, 02:00 $\mathrm{h}$ and 03:30 after the beginning of the simulation.

this paper. Note that this term does not refer to the commonly used colloquialism for solid $\mathrm{CO}_{2}$.

After about one hour into the simulation, convection starts to develop leading to significant ice contents up to about $16 \mathrm{~km}$ altitude (Fig. 1a, b and c). The top part of the convective cloud is mainly composed of pristine ice (up to $0.9 \mathrm{~g} \mathrm{~kg}^{-1}$ at $\left.14 \mathrm{~km}\right)$ and the lower part by falling aggregates (up to $0.9 \mathrm{~g} \mathrm{~kg}^{-1}$ at $10 \mathrm{~km}$ ). Snow mixing ratios have intermediate values (up to $0.7 \mathrm{~g} \mathrm{~kg}^{-1}$ at $14 \mathrm{~km}$ ) because once large values are reached snow is converted in the model into aggregates. After two hours (Fig. 1d, 1e and f) the convective updraft is less intense leading to lower total ice contents. The cell has travelled North-eastwards due to advection and developed a stratiform part. At this stage, pristine ice mixing ratios are still large. Aggregates have had sufficient time to grow and to sediment leading to values up to $0.6 \mathrm{~g} \mathrm{~kg}^{-1}$ around $9 \mathrm{~km}$ altitude. Later in the simulation (Fig. $1 \mathrm{~g}$, $\mathrm{h}$ and i) the convective cell is in a dissipating stage. The remaining dry ice is mainly in the $12-14 \mathrm{~km}$ altitude range and composed of slow falling pristine and snow crystals. The mixing ratios of both pristine ice and snow decrease as a function of time with a maximum of $0.30-0.35 \mathrm{~g} \mathrm{~kg}^{-1}$ after $2 \mathrm{~h}$ of simulation down to a maximum of $0.2 \mathrm{~g} \mathrm{~kg}^{-1}$ after $3.5 \mathrm{~h}$ of simulation.

The results for the RUN1M simulations are displayed in Fig. 2. The general development of the ice in the convective cell is similar to the REF simulation. The RUN1M gives mixing ratios for dry ice of the same order of magnitude but slightly larger $(\sim 20 \%)$ than the REF simulation during the whole simulation. It also provides less pristine ice and more snow and aggregates showing that pristine ice is more rapidly converted into snow and aggregates in the RUN1M simulation. 

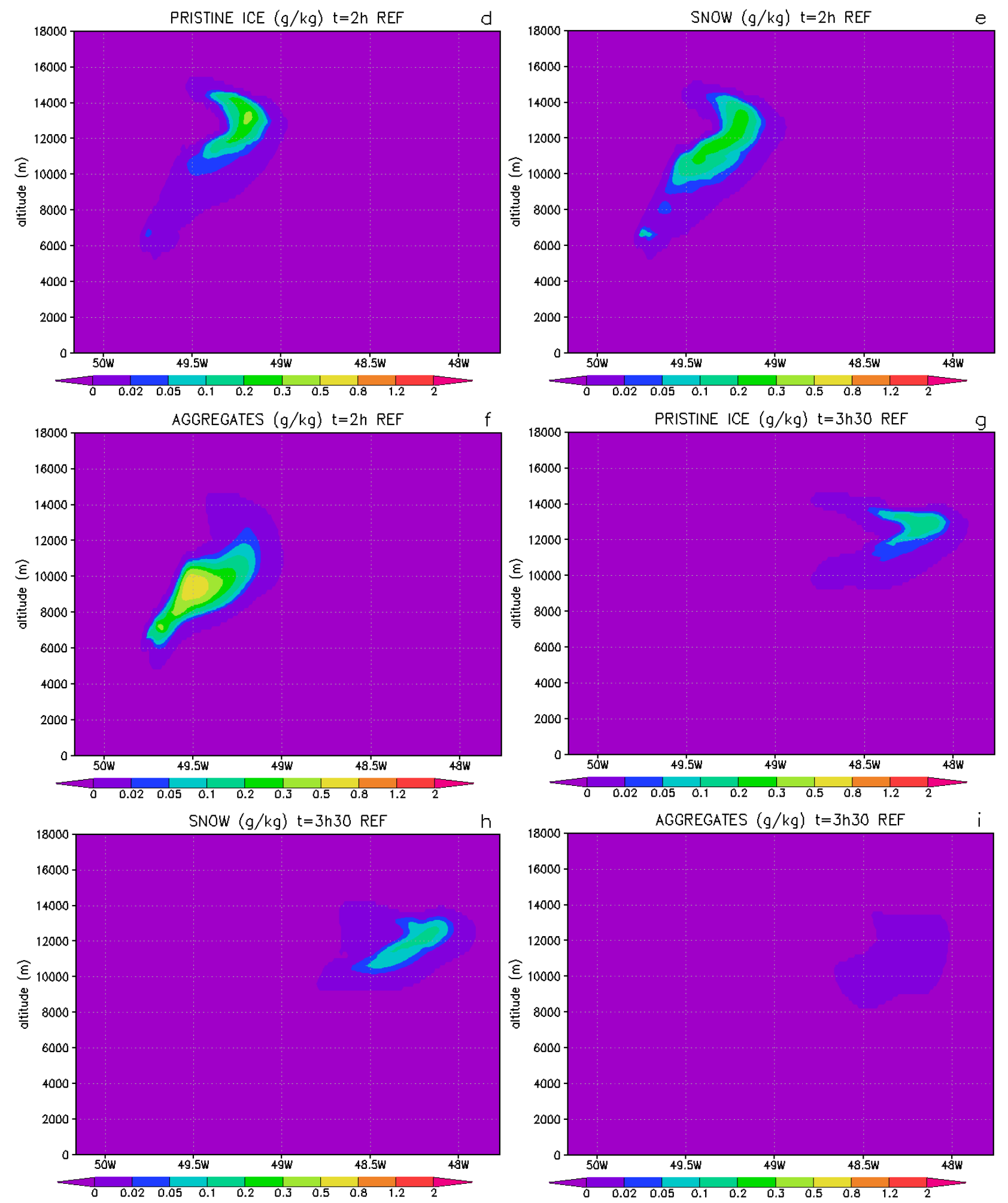

Fig. 1. Continued. 

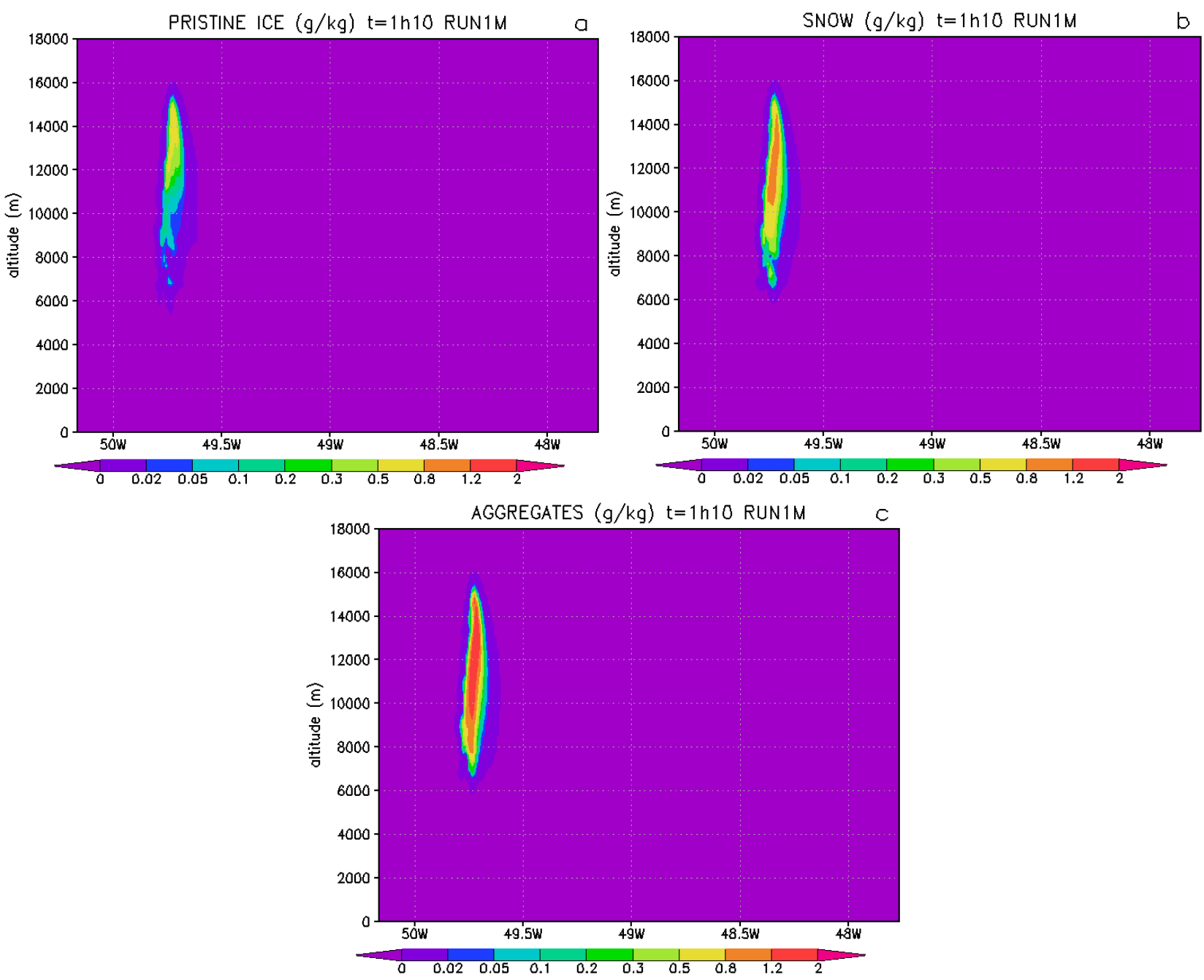

Fig. 2. Same as Fig. 1 but for the RUN1M simulation.

\subsection{Air parcel trajectories}

Trajectories are calculated from the simulation outputs using the trajectory model developed by Freitas et al. (2000). The seven trajectories selected illustrate all the different types of microphysical evolution experienced by dry ice particles above the $235 \mathrm{~K}$ isotherm in the 3-D convective cloud simulation. This is the information of temperature, water vapour and ice mixing ratios, ice concentrations that is interpolated along these trajectories and they are then used in a box model for the Langmuir and trapping calculations. Altitudes as a function of time for the seven trajectories of the REF run are displayed in Fig. 3a. Two of the trajectories (purple and light blue lines in Fig. 3a) come from the lower troposphere and are uplifted by the convective updraft. Liquid and then ice particles are formed in these air parcels. One trajectory (dark green line) intercepts the convective updraft in the midtroposphere. The other four start and stay in the upper troposphere (dark blue, light green, orange and red lines). Figure $3 b$ shows the evolution of temperature along the seven trajectories. In the upper troposphere, temperatures range from $235 \mathrm{~K}$ to $203 \mathrm{~K}$. Dry ice particles are first found on all trajectories between 1.07 and 1.20 hours after the beginning of the simulation (Fig. 4a). Water vapour deposition occurs when saturation above ice is larger than 1 . Figure 4a shows that dry ice is found initially in sub-saturated conditions for the 4 upper tropospheric trajectories (orange, red, light green and dark blue) and for the trajectory coming from the midtroposphere (dark green). For these trajectories dry ice in the air parcels considered comes initially from the interception of the air parcel by the convective updraft. Figure $4 b, c$ and $d$ show pristine ice, snow and aggregates as a function of time along the 7 trajectories. At the beginning of the trajectories, pristine ice, snow and aggregates mixing ratios are similar. At the end of the simulation pristine ice is the main ice category. The snow mixing ratio is smaller than the pristine mixing ratio but still significant. The mixing ratio of aggregates is very low and negligible with respect to snow and pristine ice. 

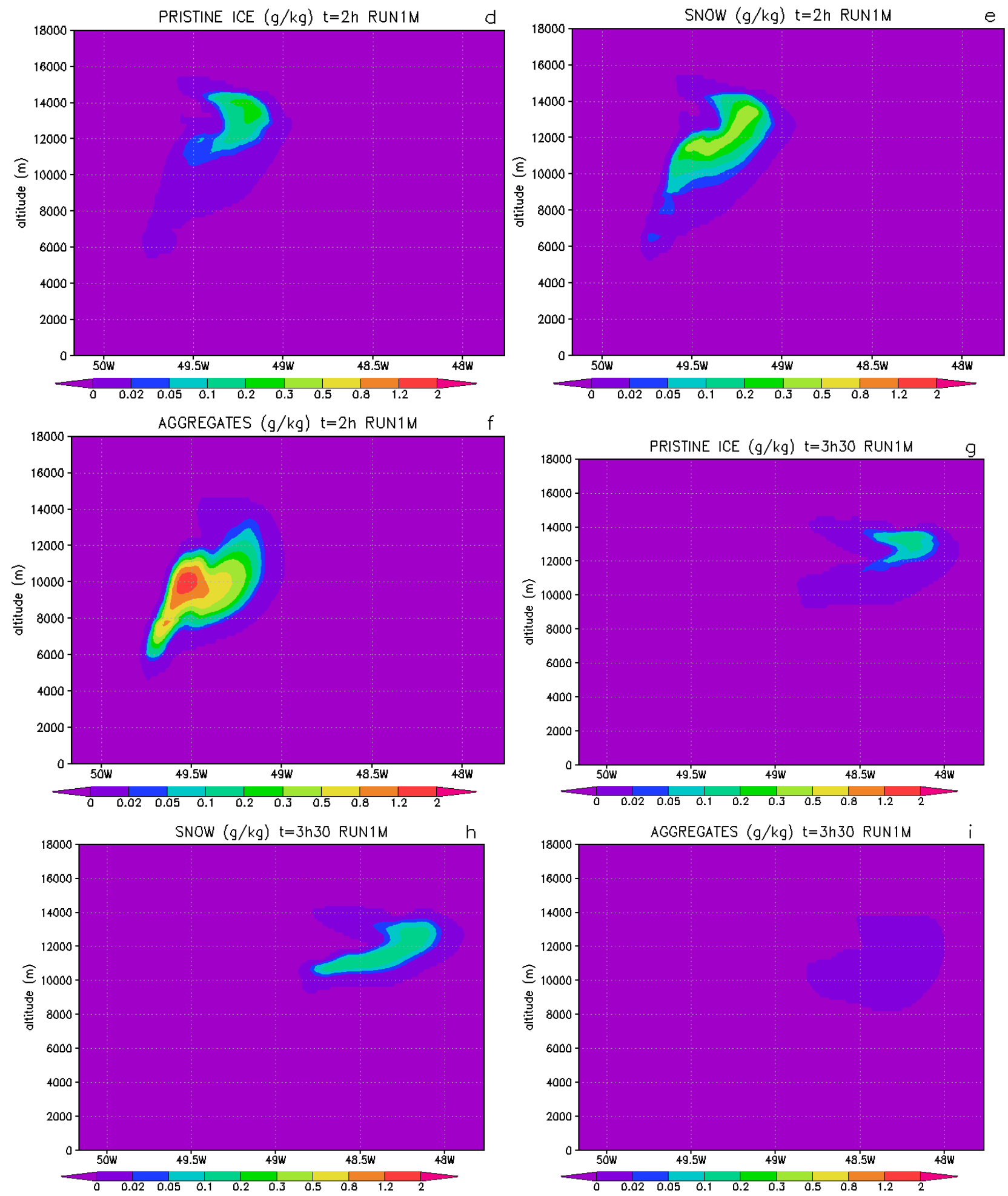

Fig. 2. Continued. 

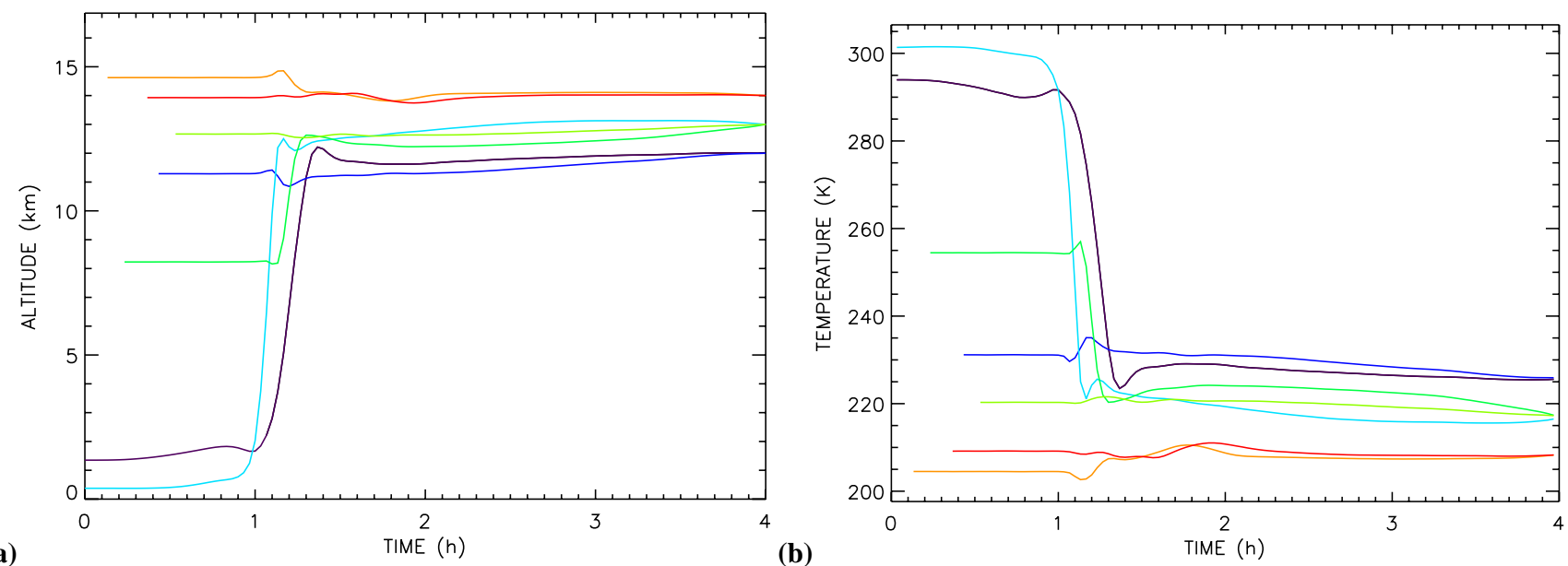

Fig. 3. Air parcel trajectories selected for the REF simulation. (a) altitude versus time and (b) temperature versus time.
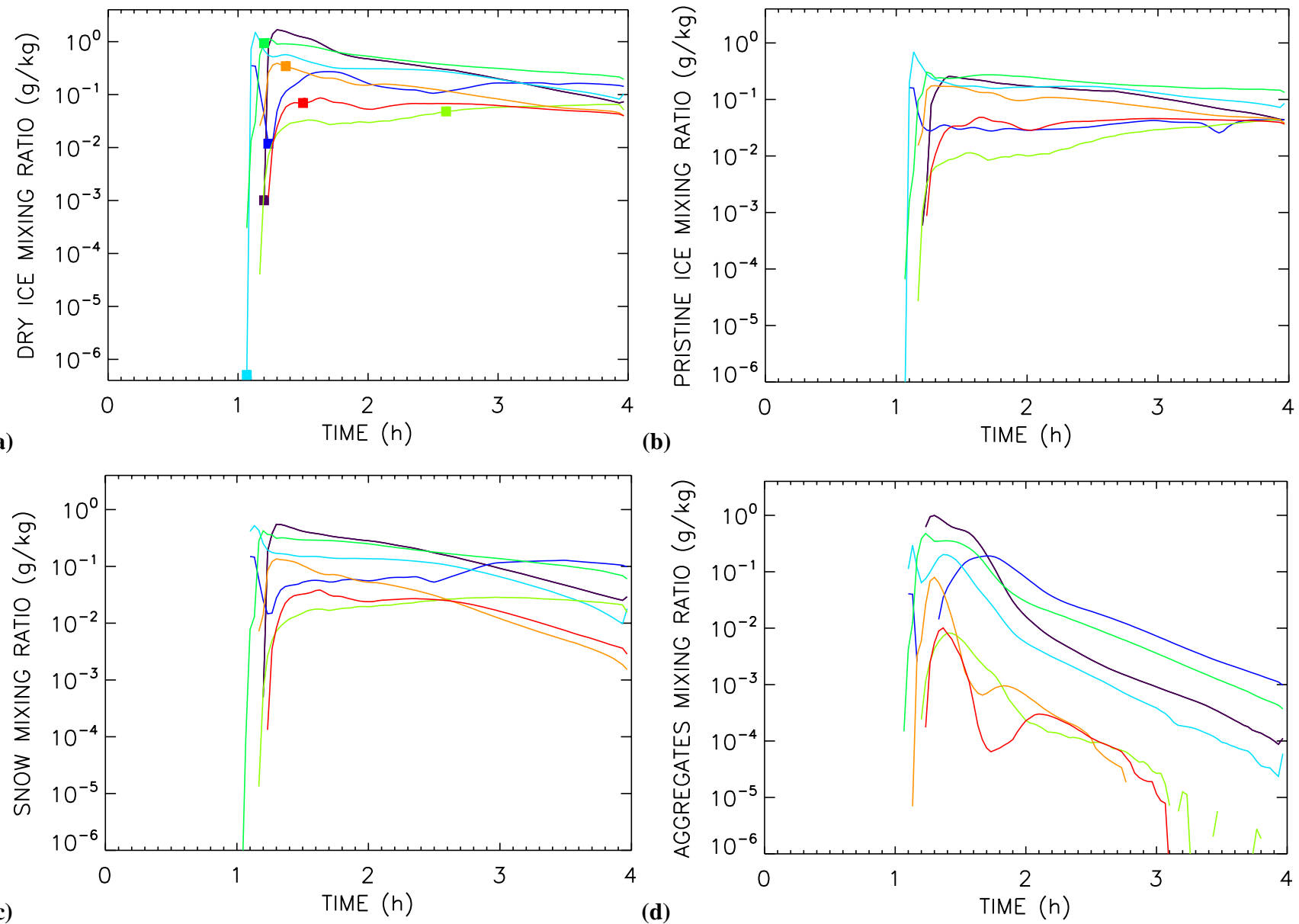

Fig. 4. (a) Dry ice mixing ratio in $\mathrm{g} \mathrm{kg}^{-1}$ versus time, (b) Pristine ice mixing ratio in $\mathrm{g} \mathrm{kg}^{-1}$ versus time, (c), snow mixing ratio in $\mathrm{g} \mathrm{kg}^{-1}$ versus time and (d) aggregates mixing ratio in $\mathrm{g} \mathrm{kg}^{-1}$ versus time along the selected trajectories from the REF simulation. The dry ice mixing ratio is defined as the sum of pristine ice, snow and aggregates mixing ratios. On each trajectory of Fig. 4a, the full square indicates the time at which ice begins to grow by water vapour deposition. 

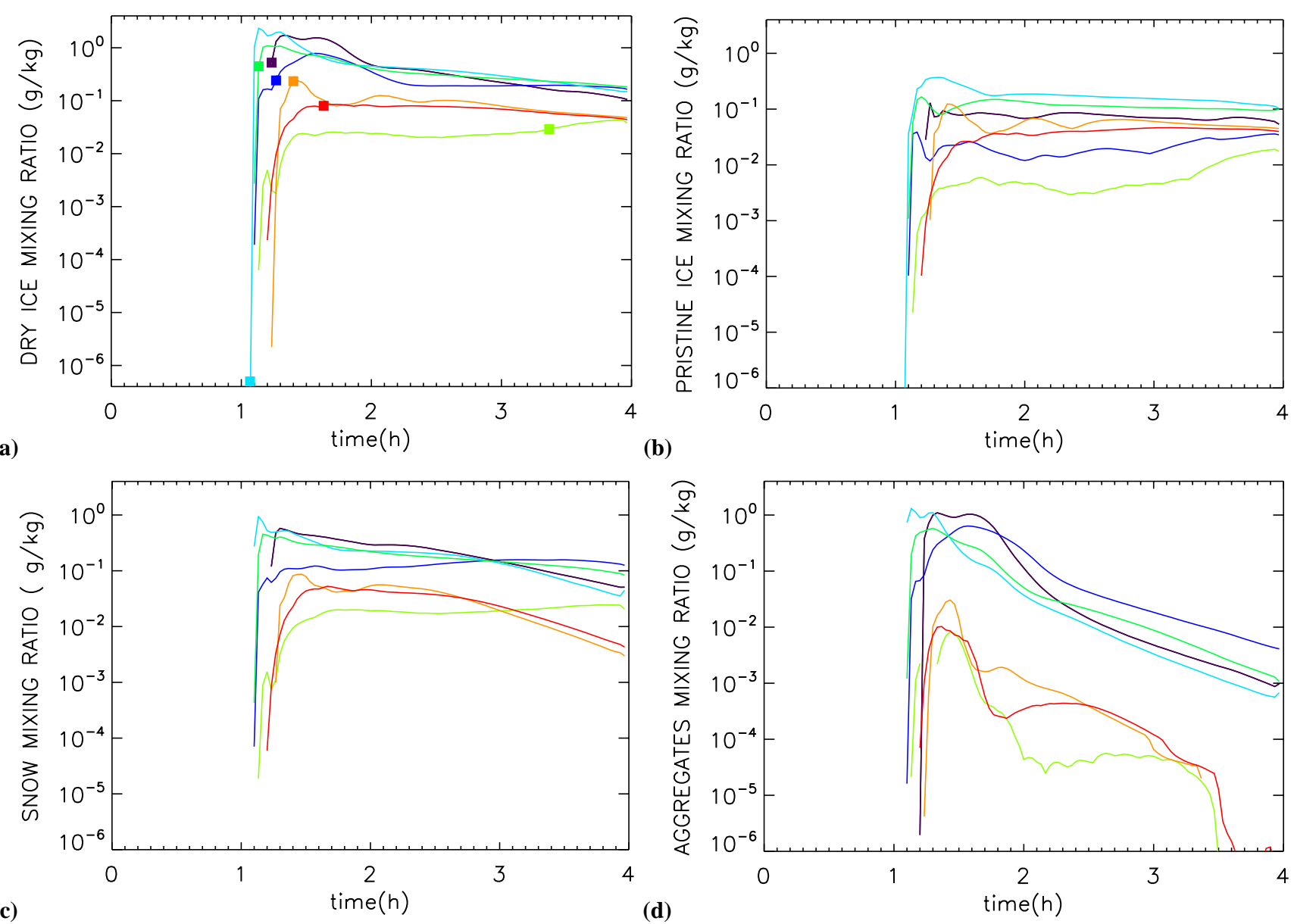

Fig. 5. Same as Fig. 4 but for the RUN1M simulation.

The 7 trajectories in the RUN1M simulation, ending at the same location as in the REF simulation are displayed in Fig. 5. The RUN1M simulation shows a similar general behaviour as in REF for the altitude, the temperature and the dry ice mixing ratio as a function of time. Snow and aggregates mixing ratios are larger in the RUN1M simulation than in the REF simulation (Fig. $5 c$ and d). On the contrary pristine ice mixing ratios are lower in the RUN1M simulation than in the REF simulation (Fig. 5b). This is consistent with the comparison between Figs. 1 and 2.

\section{Description and results of the Langmuir approach}

\subsection{The Langmuir theory}

The Langmuir theory establishes the equilibrium between the gas phase concentration of each species and the ice surface concentration for reversible adsorption of the species by ice particles. In this approach, it is assumed that the number of adsorbed molecules per ice surface unit cannot be higher than a maximum value $N_{\mathrm{MAX}}$. This maximum number is measured in laboratory for each species. It does not usually depend on temperature. Assuming equilibrium between the adsorption flux and the desorption flux leads to the relation between the species concentration on the ice surface $n_{S}$ (molecules $\mathrm{cm}^{-3}$ of air) and the gas concentration $n_{G}$ (molecules $\mathrm{cm}^{-3}$ of air) if the interaction is non-dissociative:

$n_{S}=A \theta N_{\mathrm{MAX}}$

where A is the surface area of the ice particles $\left(\mathrm{cm}^{2} \mathrm{~cm}^{-3}\right)$, $N_{\text {MAX }}$ is in molecules $\mathrm{cm}^{-2}$ and $\theta$ is the fractional coverage of the ice surface.

The fractional coverage is defined by:

$\theta=\frac{\frac{K_{\operatorname{linC}}}{N_{\mathrm{MAX}}} n_{G}}{1+\frac{K_{\operatorname{linC}}}{N_{\operatorname{MAX}}} n_{G}}$

where $K_{\text {linC }}(\mathrm{cm})$ is the partition coefficient. This coefficient is measured in laboratory studies and depends on trace gas. It usually increases when temperature decreases. 
For low gas concentrations, $n_{G}$, the denominator in relationship (Eq. 5) is close to 1 which leads to a linear dependence of $n_{S}$ on $n_{G}$ :

$n_{S}=A K_{\operatorname{linC}} n_{G}$

For higher gas concentrations, saturation occurs ( $\theta$ close to 1 ) and leads to the decrease of the ratio $\frac{n_{S}}{n_{G}}$ when $n_{G}$ increases. The limit between the low concentrations, for which the surface concentration is proportional to the gas phase concentration, and the high concentrations, for which saturation occurs, depends on $K_{\operatorname{linC}}$ and therefore on the trace gas considered.

In the case of a competitive adsorption of two or more trace gases a modified form of the Langmuir isotherm must be used. For two trace gases $i$ and $j$ in competition the relation (Eq. 4) must be written:

$n_{\mathrm{Si}}=\frac{A K_{\operatorname{linC}_{i}} n_{G i}}{1+\frac{K_{\operatorname{linc}_{i}}}{N_{\mathrm{MAX}_{i}}} n_{G i}+\frac{K_{\operatorname{linc}_{j}}}{N_{\mathrm{MAX}_{j}}} n_{G j}}$

where index $i$ refers to trace gas $i$ and index $j$ to trace gas $j$.

In this case, trace gases in contact with the surface are assumed to compete for similar adsorption sites (e.g. von Hessberg et al., 2008). Such competive adsorption has been applied to calculate the surface concentration of $\mathrm{HCl}$ (needed e.g. for heterogeneous procesing rates of $\mathrm{ClONO}_{2}$ ) in the presence of $\mathrm{HNO}_{3}$ (IUPAC, 2009; http://www.iupac-kinetic. ch.cam.ac.uk).

The temperature dependency of $K_{\text {linC }}$ is given by $K_{\text {linC }}=$ $A_{P} \exp \left(B_{P} / T\right)$. Table 1 gives the parameters $A_{P}$ and $B_{P}$ for the 11 species $\mathrm{HCl}, \mathrm{HNO}_{3}, \mathrm{PAN}, \mathrm{H}_{2} \mathrm{O}_{2}, \mathrm{HCHO}$, $\mathrm{CH}_{3} \mathrm{OH}, \mathrm{C}_{2} \mathrm{H}_{5} \mathrm{OH}, \mathrm{C}_{3} \mathrm{H}_{7} \mathrm{OH}, \mathrm{HCOOH}, \mathrm{CH}_{3} \mathrm{COOH}$ and $\mathrm{CH}_{3} \mathrm{COCH}_{3}$ taken into account in this paper as well as $N_{\text {MAX. }}$. These species were chosen because partition coefficients have been evaluated by the IUPAC Subcommittee on Gas Kinetic Data Evaluation (Crowley et al., 2010 and http://www.iupac-kinetic.ch.cam.ac.uk). Table 1 gives the temperature range avaibility of $K_{\text {linC }}$ evaluated by IUPAC. For $\mathrm{H}_{2} \mathrm{O}_{2}$, we also used preliminary results of the Max Planck Insitute fur Chemie in Mainz which will be reported in detail elsewhere (Pouvesle et al., manuscript in preparation, 2010).

Briefly, partition coefficients for $\mathrm{H}_{2} \mathrm{O}_{2}$ were obtained in the MPI laboratory at temperatures between 203 and $233 \mathrm{~K}$ in the same apparatus used to study the interaction of several oxidized organic trace gases with ice surfaces at upper tropospheric temperatures (Winkler et al., 2002; von Hessberg et al., 2008). Results were obtained using both single species adsorption of $\mathrm{H}_{2} \mathrm{O}_{2}$ and a competitive approach, whereby the displacement of $\mathrm{HC}(\mathrm{O}) \mathrm{OH}$ from the ice surface by adsorbed $\mathrm{H}_{2} \mathrm{O}_{2}$ was examined. Both methods yielded consistent results and values obtained in the more reliable single species adsorption experiments may be summarisd as $K_{\text {linC }}(203-$ $233 \mathrm{~K})=2.1 \times 10^{-5} \exp (3800 / \mathrm{T}) \mathrm{cm}$. The value calculated

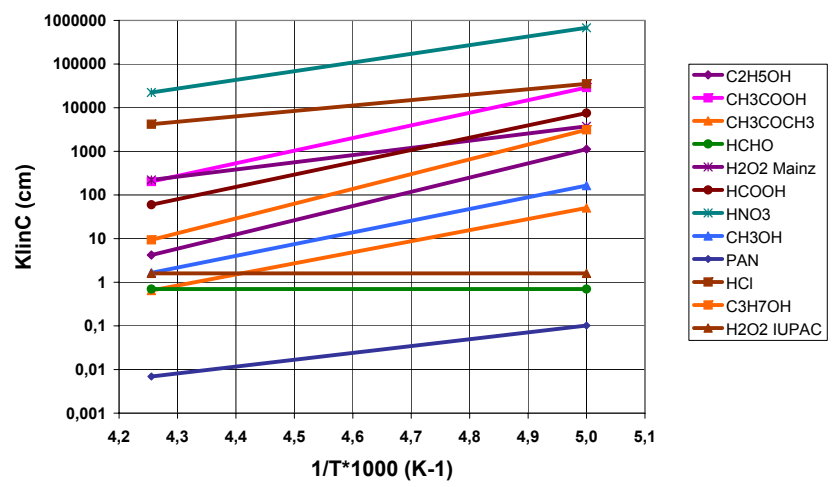

Fig. 6. Partition coefficients $(\mathrm{cm})$ used in the calculations as a function of the inverse of the temperature, extrapolated in the range $200 \mathrm{~K}-235 \mathrm{~K}$.

at $228 \mathrm{~K}\left(K_{\text {linC }} \approx 360 \mathrm{~cm}\right)$ is thus more than 2 orders of magnitude larger than the value of $1.6 \mathrm{~cm}$, reported by Clegg and Abbatt (2001) for the temperature range 228-240 K.

Figure 6 shows the partition coefficient $K_{\operatorname{linC}}$ for the 11 trace gases as a function of the temperature. They are extrapolated when needed in the range $200-235 \mathrm{~K}$ from the IUPAC data. Table 1 and Fig. 6 show that for various trace gases large differences exist between the absolute value of the partition coefficients at any one temperature and on their temperature dependence. In contrast, the maximum number of molecules $N_{\text {MAX }}$ adsorbed on the ice surface is similar for all the trace gases as it is largely a characteristic of the ice surface (e.g. number of active adsorption sites) for the small molecules considered here.

In the model, an instantaneous equilibrium was assumed between the ice surface concentration and the gas phase concentration at each time step of the calculations. This assumption will be justified in Sect. 3.3.

\subsection{Surface area of the ice particles}

The ice surface area is required to determine relation (Eq. 4). For the total number of ice particles in an air parcel, assuming that all particles of the same category in the same size class have the same surface, the ice surface area, $A$, is given by:

$A=\sum_{i=1}^{m} A_{i}=\sum_{i=1}^{m}\left(\int_{0}^{\infty} \sigma_{i}(D) n_{i}(D) d D\right)$

where $i$ refers to one of the model ice categories, $m$ is the number of ice categories. As previously explained we only take into account pristine ice, snow and aggregate categories $(m=3) . \sigma_{i}$ is the surface of each individual ice particle, $D$ is the diameter of an equivalent spherical particle having the same volume as the actual ice particle and $n_{i}(D)$ is the size distribution of each ice category given by relation (Eq. 1).

In the two microphysical schemes of the BRAMS model, the geometrical form of pristine ice and snow are diagnosed 
Table 1. Parameters $A_{P}$ and $B_{P}$ used to compute the partition coefficient. $K_{\text {linC }}$, maximum number of molecules $N_{\text {MAX }}$ adsorbed on the ice surface and temperature range avaibility for the 11 species taken into account in the present paper.

\begin{tabular}{lllll}
\hline Species & $A_{P}(\mathrm{~cm})$ & $B_{P}\left(\mathrm{~K}^{-1}\right)$ & $N_{\text {MAX }}\left(\mathrm{cm}^{-2}\right)$ & Temperature range $(\mathrm{K})$ \\
\hline $\mathrm{C}_{2} \mathrm{H}_{5} \mathrm{OH}$ & $5.8 \times 10^{-14}$ & 7500 & $2.8 \times 10^{14}$ & $210-250$ \\
$\mathrm{CH}_{3} \mathrm{C}(\mathrm{O}) \mathrm{OH}$ & $1.0 \times 10^{-10}$ & 6660 & $2.4 \times 10^{14}$ & $195-240$ \\
$\mathrm{CH}_{3} \mathrm{COCH}$ & $1.0 \times 10^{-11}$ & 5850 & $2.7 \times 10^{14}$ & $195-230$ \\
$\mathrm{HCHO}$ & $7.0 \times 10^{-01}$ & 0 & $2.7 \times 10^{14}$ & $198-233$ \\
$\mathrm{HC}(\mathrm{O}) \mathrm{OH}$ & $5.8 \times 10^{-11}$ & 6500 & $2.2 \times 10^{14}$ & $187-221$ \\
$\mathrm{CH}_{3} \mathrm{OH}$ & $6.2 \times 10^{-12}$ & 6180 & $3.2 \times 10^{14}$ & $195-230$ \\
$\mathrm{H}_{2} \mathrm{O}_{2} \mathrm{IUPAC}$ & 1.6 & 0 & $2.7 \times 10^{14 \mathrm{a}}$ & $228-240$ \\
$\mathrm{H}_{2} \mathrm{O}_{2} \mathrm{Mainz}$ & $2.1 \times 10^{-05}$ & 3800 & $2.7 \times 10^{14 \mathrm{a}}$ & $203-233$ \\
$\mathrm{HNO}_{3}$ & $7.5 \times 10^{-05}$ & 4585 & $2.7 \times 10^{14}$ & $214-240$ \\
$\mathrm{PAN}$ & $1.5 \times 10^{-09}$ & 3608 & $2.7 \times 10^{14 a}$ & $200-220$ \\
$\mathrm{C}_{3} \mathrm{H}_{7} \mathrm{OH}$ & $3.6 \times 10^{-14}$ & 7800 & $3.1 \times 10^{14}$ & $228^{\mathrm{b}}$ \\
$\mathrm{HCl}$ & $2.2 \times 10^{-02}$ & 2858 & $3.0 \times 10^{14}$ & $205-230$ \\
\hline
\end{tabular}

${ }^{\text {a }} N_{\text {MAX }}$ is not available for this species in the IUPAC subcommittee assessment. In this case $N_{\text {MAX }}$ is assumed to be $2.7 \times 10^{14} \mathrm{~cm}^{-2}$ which is the median value of the other species assessed by IUPAC. ${ }^{\mathrm{b}}$ The measurement of $K_{\text {linC }}$ has been made only at $228 \mathrm{~K}$. The temperature dependence was estimated from the observed similar temperature depencies for $\mathrm{C}_{2} \mathrm{H}_{5} \mathrm{OH}$ and $\mathrm{C}_{4} \mathrm{H}_{9} \mathrm{OH}$.

during the simulation at each grid point and timestep depending on air temperature and relative humidity. Contrarily to what is used in the BRAMS 3-D simulations, we have only assumed one type of ice crystals for pristine and one for snow along all the trajectories. This allow us to make a clear interpretation of the results. This assumption was supported by the results from the REF simulation that showed that the predominant geometrical form for both pristine ice and snow was by far the hexagonal column. Therefore this geometrical form was assumed for these two categories of ice in the Langmuir uptake approach. The aspect ratio which gives the relation between the length of the hexagone $d$ and the length $\mathrm{L}$ of the columns is set to $d=2.5 L^{0.6}$ as in Wyser and Yang (1998) who fitted to the data given in Hobbs (1974). For aggregates the geometrical form is more complex. Here it is assumed that they are formed of $n$ hexagonal columns and that the surface and the volume of each aggregate particle are $\mathrm{n}$ times the surface and the volume of an individual hexagonal column. This leads to the following ice surface area for each ice category:

$$
A_{i}=N_{t, i} n_{i}\left[\left(0.0677 / n_{i}^{6 / 11}\right) D_{n, i}^{1.636}+\left(158 / n_{i}^{8 / 11}\right) D_{n, i}^{2.182}\right]
$$

where $A_{i}\left(\mathrm{~m}^{2} \mathrm{~m}^{-3}\right)$ is the surface area of the ice category $i, D_{n, i}(\mathrm{~m})$ is the characteristic diameter of the distribution, $N_{t, i}\left(\mathrm{~m}^{-3}\right)$ is the ice category concentration and $n_{i}$ is the number of hexagonal columns forming the ice particle; $g_{i}$ is 1 for pristine ice and snow. It has been assumed to be 4 for aggregates in the REF and the RUN1M simulation.

$D_{n, i}$ and $N_{t, i}$ are provided at each time step by the microphysical scheme of the BRAMS model. Note that in the RUN1M simulation $D_{n, i}$ is set to a constant value for snow and aggregates while it is a prognostic variable in the REF simulation.

The choice of the number, $n$, of hexagonal columns which compose the aggregates is arbitrary. Choosing $n=8$ or $n=2$ leads to a change in the surface area of only $\pm 23 \%$ relative to $n=4$. The reason for this relatively small change in the surface area is that $\sigma_{i}$ in Eq. (8) is a function of the diameter D of an equivalent spherical particle having the same volume as the actual ice particle: increasing or decreasing the number of hexagonal columns per aggregates is partially balanced by the decrease or the increase of the volume and of the surface of each hexagonal column. Sensitivity tests on the number $\mathrm{n}$ of hexagonal column per aggregates in the Langmuir approach are presented in Sect. 3.3.

The total surface area of dry ice particles has been computed for the 7 selected trajectories of the REF simulation (Fig. 7). It gives values between $2 \times 10^{3} \mu \mathrm{m}^{2} \mathrm{~cm}^{-3}$ and $2 \times 10^{4} \mu \mathrm{m}^{2} \mathrm{~cm}^{-3}$ on the high altitude trajectories. These values are consistent with the measurements made during the CRYSTAL-FACE experiment in Florida (Popp et al., 2004) in which surface areas between $2 \times 10^{2} \mu \mathrm{m}^{2} \mathrm{~cm}^{-3}$ and $4 \times 10^{4} \mu \mathrm{m}^{2} \mathrm{~cm}^{-3}$ have been derived from the measurements of two independent instruments, the Cloud, Aerosol and Precipitation Spectrometer (Baumgardner et al., 2001) and the Cloud Integrating Nephelometer (Gerber et al., 2000). In the ascending part of the trajectories the surface area can reach $1.5 \times 10^{5} \mu \mathrm{m}^{2} \mathrm{~cm}^{-3}$ due to the large ice mixing ratios observed on this part of the trajectories.

As already discussed, the size distribution of the pristine ice category has a smaller characteristic diameter $D_{n, i}$ than the snow category. For the same mixing ratio, the surface area of the pristine ice category is expected to be larger than 


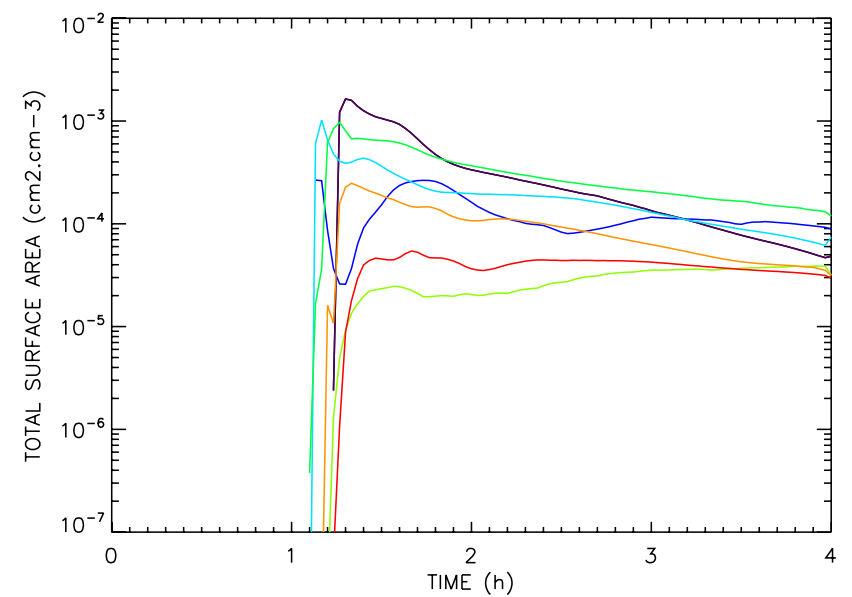

Fig. 7. Total surface area $\left(\mathrm{cm}^{2} \mathrm{~cm}^{-3}\right)$ computed on the 7 trajectories in the REF simulation.

the surface area of the snow category because of the larger number of pristine ice crystals. This is confirmed by the results of Fig. 8 which shows the ratio of the surface area of snow over the surface area of pristine ice as a function of the ratio of the mixing ratio of snow over the mixing ratio of pristine ice. We observe in particular that if the snow mixing ratio is the same as the pristine ice mixing ratio (ratio of mixing ratio is 1) the surface area of snow is smaller than the surface area of pristine ice (ratio of surface area smaller than 1). This figure also shows that the aggregates category, which has a smaller number of crystals than the pristine ice and the snow categories, has nevertheless a larger surface area than these two categories. This is due to the fact that the individual surface of each aggregate is larger than the individual surface of pristine ice and snow crystals for the same equivalent diameter $D$.

\subsection{Results}

Calculations of the uptake of trace gases by the ice surface using the Langmuir approach were performed using the ice mixing ratios for pristine ice, snow and aggregates along the seven trajectories. For each species the sum of the mixing ratio in the gas phase and of the mixing ratio on the ice surface is assumed to be conserved along the trajectories although this hypothesis is not fully satisfying, owing to sedimentation and turbulent mixing processes modifying the total (gas + gas adsorbed on ice surface) species mixing ratio. Nevertheless, the ratio of the gas phase mixing ratio on the total mixing ratio at each timestep of the simulation is a parameter independent on the history on the trajectories from which it is possible to assess the importance of the ice uptake of the considered species. In order to take into account the range of total mixing ratios possibly encountered in the atmosphere, the calculations were done with different total mixing ratio up to 10 ppbv.

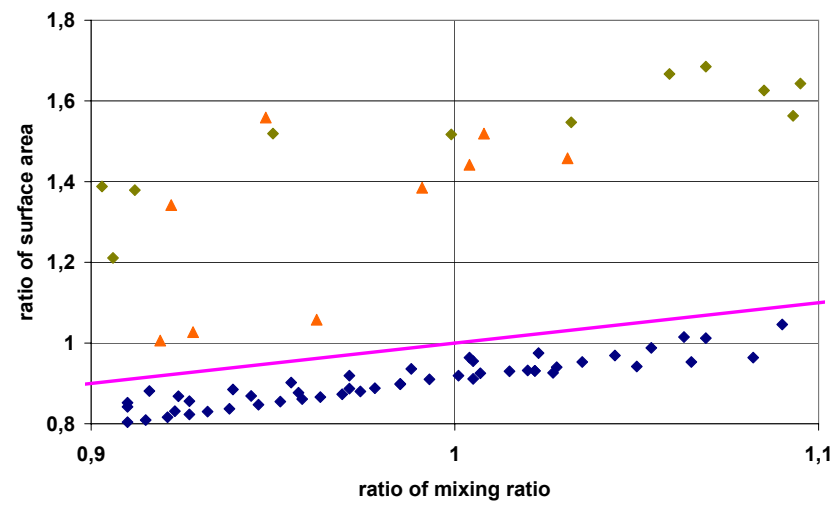

Fig. 8. Ratio of the surface area of snow over the surface area of pristine ice as a function of the ratio of the mixing ratio of snow over the mixing ratio of pristine ice (blue diamonds); the same for aggregates and pristine ice (orange triangles) and for aggregates and snow (green diamonds). The pink line is the location of the points for which a ratio of the mixing ratio would lead to the same ratio of the surface area.

In these calculations a timestep of $120 \mathrm{~s}$ was chosen. We checked that this timestep is sufficient to reach the equilibrium. For this we calculated the rate constant $R\left(\mathrm{~s}^{-1}\right)$ to reach the equilibrium:

$R=k_{\mathrm{des}}+\frac{\alpha u A(1-\theta)}{4}$

where $k_{\text {des }}$ is the desorption rate, $\alpha$ is the accommodation coefficient, $u$ is the thermal velocity of the gas species, $A$ is the surface area of the ice particles and $\theta$ is the fractional coverage of the ice surface $(0<\theta<1)$. The time $\tau$ to reach the equilibrium is $\tau=1 / R$. It depends on the species, on the gas phase concentration and on the characteristics of the air parcels. In the range of the gas concentration assumed in the present paper (mixing ratio lower than $10 \mathrm{ppbv}$ ) and on average over all the trajectories $\tau$ aries between $3 \mathrm{~s}$ and $45 \mathrm{~s}$ depending on the species. Since the time step of the ice uptake calculations is $120 \mathrm{~s}$, the assumption of an instantaneous equilibrium between the gas phase and the ice surface concentration is justified.

Table 2 gives the mean mixing ratio, the standard deviation and the minimum mixing ratio in the gas phase of the 11 species computed when dry ice is present in the 7 selected trajectories from REF simulation. A constant total mixing ratio of $100 \mathrm{pptv}$ (gas phase+species adsorbed on the ice surface) has been used in these calculations. On average over the 7 trajectories the uptake of $\mathrm{HNO}_{3}$ and $\mathrm{HCl}$ by ice particles is very large (approximately $85 \% \pm 15 \%$ for $\mathrm{HNO}_{3}$ and $50 \% \pm 20 \%$ for $\mathrm{HCl}$ ). It is lower but significant for $\mathrm{CH}_{3} \mathrm{COOH}$ (approximately $18 \% \pm 14 \%$ ) and $\mathrm{HCOOH}$ $(6 \% \pm 6 \%)$. For these 2 species the maximum uptake can be large with $68 \%$ and $36 \%$, respectively. For the other species $\left(\mathrm{C}_{2} \mathrm{H}_{5} \mathrm{OH}, \mathrm{HCOOH}, \mathrm{PAN}, \mathrm{HCHO}, \mathrm{CH}_{3} \mathrm{COCH}_{3}\right.$ and $\mathrm{CH}_{3} \mathrm{OH}$ ) uptake is small or negligible because they have low 
Table 2. Mean, standard deviation and minimum gas phase mixing ratio on the time interval when dry ice is present over the seven trajectories computed in the REF simulation. The total mixing ratio for all species is assumed to be 100 pptv. The results of the RUN1M simulation are given in parenthesis.

\begin{tabular}{llll}
\hline Species & $\begin{array}{l}\text { Mean mixing ratio } \\
\text { (pptv) }\end{array}$ & $\begin{array}{l}\text { Standard deviation } \\
\text { (pptv) }\end{array}$ & $\begin{array}{l}\text { Minimum mixing ratio } \\
(\text { pptv) }\end{array}$ \\
\hline $\mathrm{HNO}_{3}$ & $14.8(14.1)$ & $15.6(17.2)$ & $1.3(0.7)$ \\
$\mathrm{C}_{2} \mathrm{H}_{5} \mathrm{OH}$ & $99.2(99.1)$ & $0.9(0.9)$ & $93.2(92.7)$ \\
$\mathrm{CH}_{3} \mathrm{C}(\mathrm{O}) \mathrm{OH}$ & $82.3(79.5)$ & $13.7(14.6)$ & $31.7(27.6)$ \\
$\mathrm{CH}_{3} \mathrm{COCH}$ & $99.9(99.9)$ & $0.1(0.1)$ & $99.6(99.4)$ \\
$\mathrm{HCHO}$ & $>99.9(>99.9)$ & $0.1(0.1)$ & $99.9(99.8)$ \\
$\mathrm{HC}(\mathrm{O}) \mathrm{OH}$ & $93.7(92.5)$ & $6.0(6.5)$ & $63.3(57.8)$ \\
$\mathrm{CH}_{3} \mathrm{OH}$ & $99.8(99.8)$ & $0.2(0.2)$ & $98.7(98.2)$ \\
$\mathrm{H}_{2} \mathrm{O}_{2} \mathrm{IUPAC}$ & $>99.9(>99.9)$ & $0.1(0.1)$ & $99.7(99.5)$ \\
$\mathrm{H}_{2} \mathrm{O}_{2} \mathrm{Mainz}$ & $91.5(89.6)$ & $6.8(8.8)$ & $61.2(47.8)$ \\
$\mathrm{PAN}$ & $>99.9(>99.9)$ & $0.1(0.1)$ & $>99.9(>99.9)$ \\
$\mathrm{C}_{3} \mathrm{H}_{7} \mathrm{OH}$ & $98.1(97.8)$ & $2.3(2.3)$ & $83.8(82.7)$ \\
$\mathrm{HCl}$ & $50.9(47.2)$ & $19.7(22.4)$ & $9.3(6.1)$ \\
\hline
\end{tabular}

partition coefficients (see Fig. 6). For $\mathrm{H}_{2} \mathrm{O}_{2}$ the uptake is significant $(8 \% \pm 7 \%)$ if the partition coefficient of Pouvesle et al. (2010) is used. It is negligible if the partition coefficient of Clegg and Abbatt (2001) is used. As the photolysis of $\mathrm{H}_{2} \mathrm{O}_{2}$ can be a significant source of $\mathrm{HO}_{\mathrm{x}}\left(\mathrm{OH}, \mathrm{HO}_{2}\right)$ e.g. in the convectively influenced upper troposphere over the oceans (Prather and Jacob, 1997; Cohan et al., 1999; Collins et al., 1999), assessment of the photochemical impact of $\mathrm{H}_{2} \mathrm{O}_{2}$ in regions impacted by convective inflow requires correct values for the partition coefficient.

Figure 9a shows the mixing ratio of $\mathrm{HCl}$ in the gas phase computed in the REF simulation. A constant total mixing ratio of $100 \mathrm{pptv}$ is assumed as in Table 2. The mixing ratio decreases rapidly for all trajectories around $1.2 \mathrm{~h}$ of simulation with minimum values ranging from 0.084 to $0.009 \mathrm{ppbv}$. This corresponds to the time when large total surface areas are found on all trajectories (see Fig. 7). Then it increases with time fairly steadily for all trajectories as total surface areas decrease. The uptake efficiency, which can be defined as the ratio of the mixing ratio of $\mathrm{HCl}$ adsorbed on the ice surface over the gas mixing ratio, is also well correlated with the dry ice mixing ratio on each trajectory (Fig. 4a). Depending on the trajectory, the correlation coefficients are between 0.80 and 0.99 . Note also that the gas uptake efficiency does not depend on the origin altitude of the trajectories since low gas mixing ratios are observed on trajectories coming from the lower troposphere (purple and light blue lines) as well as from the mid-troposphere (dark green line) and from the upper troposphere (orange line).

Comparing Figs. $4 d$ and 9a shows that the ice aggregates have a larger impact on the uptake of species than pristine ice or snow. This is illustrated by the purple, dark green, light blue and dark blue trajectories. For these trajectories the variations in time of the gas mixing ratio is closely re- lated with the variations of the aggregates mixing ratio when and where this mixing ratio is significant. This is not only due to their larger mixing ratio but also to their larger surface area compared with pristine ice and snow for the same mixing ratio. At the end of the simulation, the aggregates mixing ratio is very low on the selected trajectories. As a consequence the uptake of the species is mainly dependent on the pristine ice and on the snow mixing ratios.

The results for $\mathrm{CH}_{3} \mathrm{C}(\mathrm{O}) \mathrm{OH}$ are shown in Fig. 9b. Comparing Figs. $3 \mathrm{~b}, 4 \mathrm{a}$ and $9 \mathrm{~b}$ show that uptake is not only a function of the dry ice mixing ratio. It is also a function of the temperature for trace gases having a partition coefficient strongly dependent on temperature such as $\mathrm{CH}_{3} \mathrm{C}(\mathrm{O}) \mathrm{OH}$ (Table 1). In Fig. $9 \mathrm{~b}$ the uptake is more important on the red trajectory for which the dry ice mixing ratio is small (Fig. 4a) and the temperature is low (Fig. 3b) than on the dark blue trajectory for which the dry ice mixing ratio is larger (Fig. 4a) and the temperature is higher (Fig. 3b). The influence of the temperature is emphasized in comparing the uptake of $\mathrm{CH}_{3} \mathrm{C}(\mathrm{O}) \mathrm{OH}$ (Fig. 9b) with the uptake of $\mathrm{HCl}$ (Fig. 9a) for which the partition coefficient is not strongly dependent on the temperature. Clearly uptake on the low temperature trajectories at high altitude (red and orange) is much more important for $\mathrm{CH}_{3} \mathrm{C}(\mathrm{O}) \mathrm{OH}$ than for $\mathrm{HCl}$ relative to the other trajectories.

In the Langmuir approach the trace gas mixing ratios on the ice surface evolves linearly as a function of the gas mixing ratio for low values of this gas mixing ratio. Due to saturation effects at the ice surface it increases more slowly when the gas mixing ratio is larger. The saturation effect is clearly seen for $\mathrm{HNO}_{3}$ by comparing Fig. 10a, b and c assuming respectively a total mixing ratio of $100 \mathrm{pptv}, 1 \mathrm{ppbv}$ and 10 ppbv. The gas mixing relative to the total mixing ratio is increasing when the total mixing ratio is increasing on each 

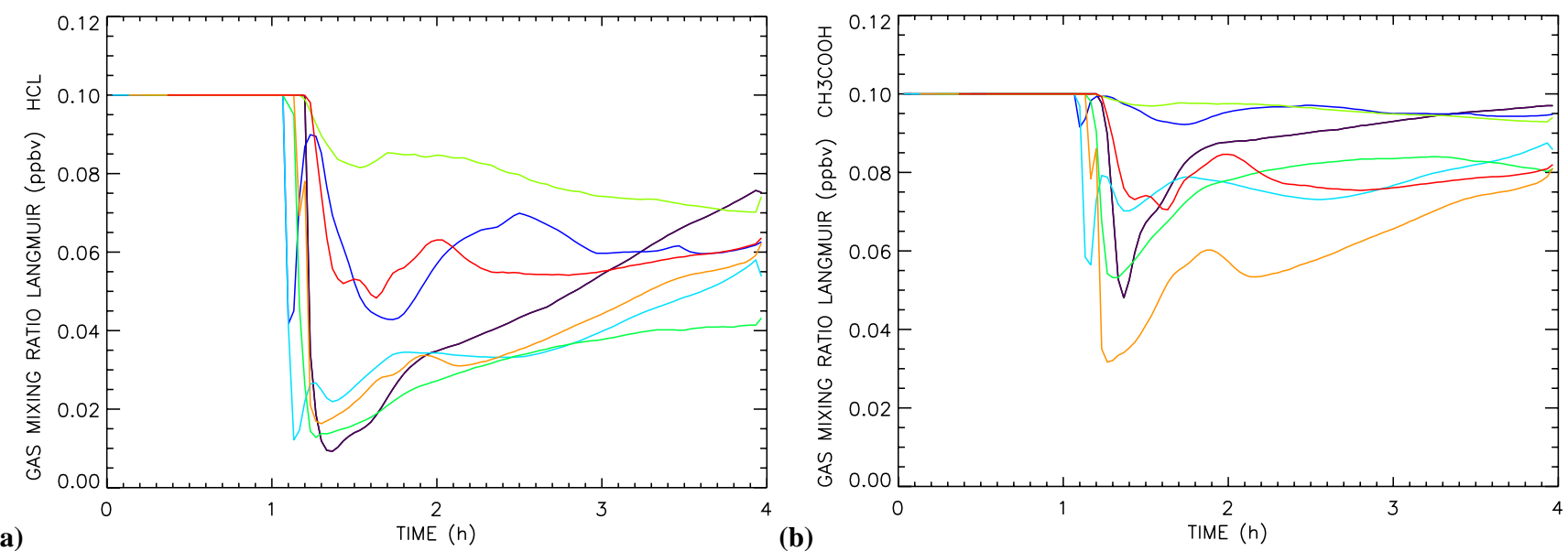

Fig. 9. Results of the Langmuir approach. (a) $\mathrm{HCl}$ gas mixing ratio versus time with an initial mixing ratio of $0.1 \mathrm{ppbv}$, (b) $\mathrm{CH}_{3} \mathrm{C}(\mathrm{O}) \mathrm{OH}$ gas mixing ratio versus time with an initial mixing ratio of $0.1 \mathrm{ppbv}$, along the selected trajectories from the REF simulation.
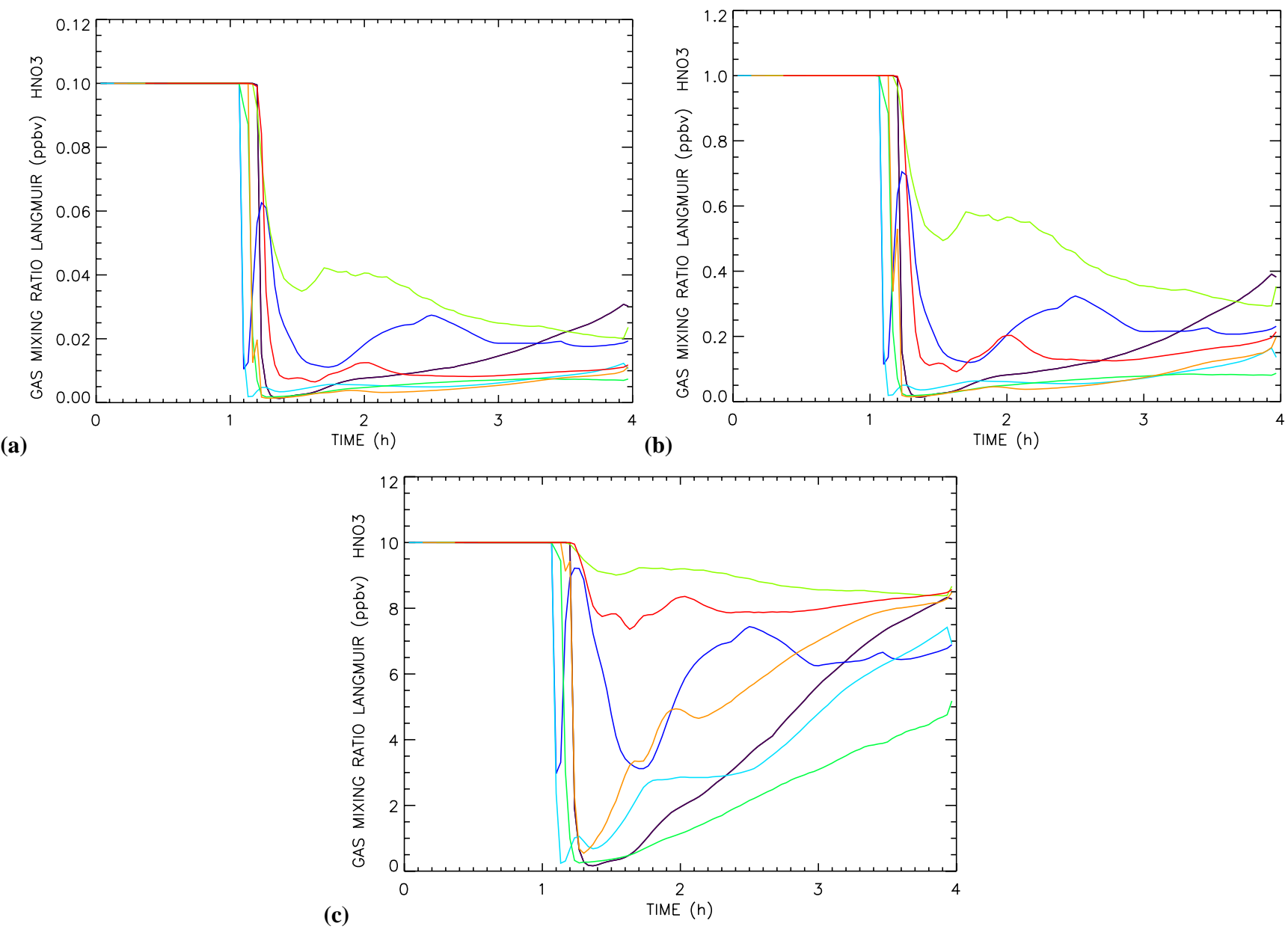

Fig. 10. Results of the Langmuir approach. $\mathrm{HNO}_{3}$ gas mixing ratio versus time along the selected trajectories from the REF simulation using an initial gas mixing ratio of (a) $0.1 \mathrm{ppbv}$, (b) $1 \mathrm{ppbv}$ and (c) $10 \mathrm{ppbv}$. 
Table 3. Impact of the number of hexagonal columns which compose an aggregate ice particle on the mean and the minimum gas phase mixing ratios of $\mathrm{HNO}_{3}, \mathrm{CH}_{3} \mathrm{COOH}$ and $\mathrm{HCl}$ along the 7 trajectories of the REF simulation. The total mixing ratio (gas+surface) for the three species is 100 pptv.

\begin{tabular}{|c|c|c|c|}
\hline Species & $\begin{array}{l}\text { Number of } \\
\text { hexagonal columns }\end{array}$ & $\begin{array}{l}\text { Mean mixing } \\
\text { ratio (pptv) }\end{array}$ & $\begin{array}{l}\text { Minimum mixing } \\
\text { ratio (pptv) }\end{array}$ \\
\hline $\mathrm{HNO}_{3}$ & 2 & 14.96 & 1.43 \\
\hline $\mathrm{HNO}_{3}$ & 4 & 14.77 & 1.30 \\
\hline $\mathrm{HNO}_{3}$ & 8 & 14.57 & 1.15 \\
\hline $\mathrm{CH}_{3} \mathrm{C}(\mathrm{O}) \mathrm{OH}$ & 2 & 82.47 & 32.60 \\
\hline $\mathrm{CH}_{3} \mathrm{C}(\mathrm{O}) \mathrm{OH}$ & 4 & 82.26 & 31.67 \\
\hline $\mathrm{CH}_{3} \mathrm{C}(\mathrm{O}) \mathrm{OH}$ & 8 & 82.02 & 30.60 \\
\hline $\mathrm{HCl}$ & 2 & 51.27 & 10.27 \\
\hline $\mathrm{HCl}$ & 4 & 50.92 & 9.26 \\
\hline $\mathrm{HCl}$ & 8 & 50.54 & 8.27 \\
\hline
\end{tabular}

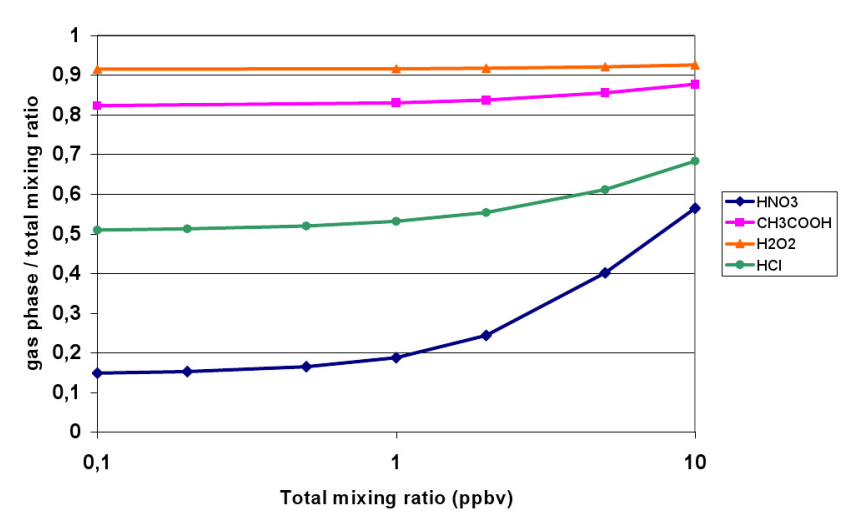

Fig. 11. Ratio of the mean gas phase mixing ratio on the total mixing ratio as a function of the total mixing ratio of $\mathrm{HNO}_{3}$, $\mathrm{CH}_{3} \mathrm{C}(\mathrm{O}) \mathrm{OH}, \mathrm{H}_{2} \mathrm{O}_{2}$ and $\mathrm{HCl}$. The total mixing ratio is defined as the sum of the gas phase mixing ratio and of the gas mixing ratio on the ice surface. For $\mathrm{H}_{2} \mathrm{O}_{2}$ the partition coefficient measured by MPIC is used.

trajectory. Figure 11 shows the ratio of the mean mixing ratio on the 7 trajectories of 4 species $\mathrm{HNO}_{3}, \mathrm{HCl}, \mathrm{CH}_{3} \mathrm{COOH}$ and $\mathrm{H}_{2} \mathrm{O}_{2}$ (MPIC) in the gas phase on the total mixing ratio as a function of the total mixing ratio. The total mixing ratio varies in the range 100 pptv- $10 \mathrm{ppbv}$. The saturation effect occurs above a total mixing ratio of approximately $1 \mathrm{ppbv}$ for $\mathrm{HNO}_{3}$ and $\mathrm{HCl}$. It is small for $\mathrm{CH}_{3} \mathrm{COOH}$ and $\mathrm{H}_{2} \mathrm{O}_{2}$. It has been checked that it is not occurring for the other species. Nevertheless if a saturation effect occurs for $\mathrm{HNO}_{3}$ or $\mathrm{HCl}$, this effect has an impact on the gas phase mixing ratio of all the other trace gases. According to relation (Eq. 7) the saturation effect of $\mathrm{HNO}_{3}$ or $\mathrm{HCl}$ leads to a decrease of the surface mixing ratio of the other trace gases if they compete for the same adsorption sites. This impact will have to be taken into account in a 3-D model.
Table 3 shows the impact of the number of hexagonal columns assumed to compose an aggregate ice particle on the gas phase mixing ratios of $\mathrm{HNO}_{3}, \mathrm{HCl}$ and $\mathrm{CH}_{3} \mathrm{COOH}$ in the 7 selected trajectories from REF simulation. For these three species the impact on the mean mixing ratio is very small: $0.3 \%$ for $\mathrm{CH}_{3} \mathrm{COOH}, 0.7 \%$ for $\mathrm{HCl}$ and $1.4 \%$ for $\mathrm{HNO}_{3}$ when the number of hexagonal columns is assumed to be 8 instead of 4 . This is explained by the smaller average mixing ratio of aggregates particles on all trajectories relative to the mixing ratios of snow and pristine ice (Fig. 4). The minimum gas mixing ratios are observed on the purple trajectory for $\mathrm{HNO}_{3}$ (Fig. 10a) and $\mathrm{HCl}$ (Fig. 9a) and on the orange trajectory for $\mathrm{CH}_{3} \mathrm{COOH}$ (Fig. 9b). On these trajectories at the time of the minimum, the ratio of the surface area of aggregates relative to the total ice surface area is large: $60 \%$ on the purple trajectory and $23 \%$ on the orange trajectory. This is the reason why the impact on the minimum gas mixing ratio is larger than on the mean gas mixing ratio: $11.5 \%$ for $\mathrm{HNO}_{3}$ and $\mathrm{HCl}$ and $3.4 \%$ for $\mathrm{CH}_{3} \mathrm{COOH}$. In general the gas phase mixing ratio is therefore not very sensitive to the exact number of hexagonal columns which compose an aggregate particle.

The results for RUN1M simulation are also given in Table 2. The mean and the minimum mixing ratios in the gas phase computed in RUN1M simulation (Table 2) are consistent but usually lower than in the REF simulation. This is mainly related to the fact that the RUN1M simulation provides larger dry ice mixing ratios along the trajectories than the REF simulation. It cannot be attributed to the temperature differences between the two simulations because they are small. 


\section{Description and results of the trapping theory for $\mathrm{HNO}_{3}$}

\subsection{The trapping theory}

In this theory, it is assumed that when ice grows by water vapour deposition, a surface-adsorbed trace gas can be trapped in the bulk of the ice particles. In contrast to reversible, surface-only adsorption, in which the adsorbed trace gas can rapidly desorb, trapped molecules are retained in the ice particles until it evaporates. From these assumptions a trapping theory was developed by Kärcher and Basko (2004). It has been recently improved by Kärcher et al. (2009) to take saturation of the uptake process on the ice surface layer into account. Following Kärcher et al. (2009) the number of gas phase particles trapped per ice particle per unit of time is defined by

$$
\frac{d N}{d t}=4 \pi r^{2} \frac{d r}{d t} n_{v}
$$

where $n_{v}$ is the species concentration trapped in the bulk of the ice, $\mathrm{r}$ is the radius of the ice particle and $\frac{d r}{d t}$ is the increase of the radius of the particle per unit of time (Pruppacher and Klett, 1997)

The bulk concentration $n_{v}$ is linked to the concentration in the gas phase by imposing continuity of the species fluxes in the gas, in the bulk and at the surface boundary. The flux at the surface boundary is a balance between the adsorption flux, taking into account surface saturation, and the desorption flux in a reference frame moving with velocity $\frac{d r}{d t}$ in the direction of increasing particle radius. The desorbed flux depends on an effective escape velocity, $v$, a result of complex processes occurring in the surface layer of the ice particle. $v$ is derived from results of laboratory studies and field measurements (Kärcher et al., 2009), the surface desorption lifetime, $\tau_{\text {des }}$, playing an important role. Up to now the escape velocity has been estimated empirically only for $\mathrm{HNO}_{3}$ using the Langmuir partition coefficient given in the IUPAC database (http://www.iupac-kinetic.ch.cam.ac.uk/). In the present paper the trapping theory is therefore only applied to $\mathrm{HNO}_{3}$. In this context, we note that $\mathrm{HNO}_{3}$ has an exceptionally long desorption time at low temperatures on ice surfaces. Based on partition coefficients and surface accommodation coefficients listed by IUPAC for $\mathrm{HNO}_{3}$, a surface residence time of $\approx 2$ minutes at $213 \mathrm{~K}$ can be calculated. Other traces gases, including the organic species and $\mathrm{H}_{2} \mathrm{O}_{2}$ studied here will have shorter residence times and are less likely to be susceptible to burial unless very large supersaturation exist. However, there are almost no laboratory data to test the trapping theory and this remains an urgent requirement to improve our understanding of trace-gas incorporation into ice particles under real conditions.
According to the detailed calculations given in Kärcher and Basko (2004) and Kärcher et al. (2009) the trapping rate per ice particle can be written:

$\frac{d N}{d t}=2 \pi D D_{\text {iff }} \varepsilon n_{G}$

where:

- $D_{\text {iff }}$ is the diffusion coefficient of species in air

- $D$ is the equivalent diameter of the ice particle

- $n_{G}$ (molecules $\mathrm{cm}^{-3}$ ) is the gas species concentration far away from the ice surface

$-\varepsilon$ is the trapping efficiency which depends on the radius of the ice particle, the increase of this radius per unit of time, the escape velocity, the accommodation coefficient $\alpha$ and the diffusion coefficient $D_{\text {iff }}$ (see Kärcher et al., 2009). $\varepsilon$ does not depend on the gas concentration $n_{G}$ except in case of saturation of the ice surface.

In the calculations the accommodation coefficient is set to $\alpha=0.3$ which is consistent with the evaluation $\alpha>0.2$ of the IUPAC Subcommittee on Gas Kinetic Data Evaluation. Finally, combining (Eq. 12) and the size distribution of the three ice categories (Eq. 1), the number of molecules per $\mathrm{cm}^{3}$ removed from the gas phase per unit of time due to trapping may be written:

$\frac{d n_{G}}{d t}=-2 \pi D_{\mathrm{iff}} n_{G} \sum_{i=1}^{m}\left(\int_{0}^{\infty} \varepsilon_{i}(D) D n_{i}(D) d D\right)$

To simplify this relation we assume that $\varepsilon_{i}(D)=\varepsilon_{i}\left(D_{\text {mean }, i}\right)$ where $D_{\text {mean }, i}$ is the mean diameter of each ice particle category. $D_{\text {mean }, i}$ is related to the characteristic diameter $D_{n, i}$ by

$D_{\text {mean }, i}=y D_{n, i}$ assuming that the shape parameter of the size distribution (Eq. 1) is $v=2$. This leads to negligible errors on $n_{G}(t)$ (lower than $1 \%$ at any time step of the calculations). Relation (Eq. 13) becomes:

$$
\frac{d n_{G}}{d t}=-2 \pi D_{\mathrm{iff}} n_{G} \sum_{i=1}^{m}\left(N_{t, i} \varepsilon_{i}\left(D_{\text {mean }, i}\right) D_{n, i} \Gamma(3) / \Gamma(2)\right)(14)
$$

From (Eq. 13), a trapping rate $k_{G}\left(\mathrm{~s}^{-1}\right)$ such as $\frac{d n_{G}}{d t}=$ $-k_{G} n_{G}$ can be derived. It is written:

$k_{G}=2 \pi D_{\mathrm{iff}} \sum_{i=1}^{m}\left(N_{t, i} \varepsilon_{i}\left(D_{\text {mean }, i}\right) D_{n, i} \Gamma(3) / \Gamma(2)\right)$

The trapping rate does not depend on the gas concentration except when saturation occurs via the $\varepsilon_{i}$ parameter. In case of saturation it decreases when $\mathrm{HNO}_{3}$ gas concentration increases. 


\subsection{Release of species in the gas phase by ice evaporation}

The release of species trapped in the bulk of the ice to the gas phase is not described by any theory at the present time. The number of molecules released by unit time depends on the location in the bulk of the trapped trace gas and an exact calculation would require a complete history of the growth and of the evaporation of each ice particle which is not available in any model. Here it is assumed that the concentration of the trace gas in the bulk of the ice particles is uniform. The number $n_{v}$ of molecules per $\mathrm{cm}^{3}$ in the bulk of the ice particles released to the gas phase is then proportional to the evaporation of the ice particles per unit of time:

$\frac{1}{n_{v}} \frac{d n_{v}}{d t}=\frac{1}{q} \frac{d q}{d t}$

where $q$ (see Eqs. 1 and 2) is the mixing ratio of the ice particles

$$
\begin{aligned}
& q=\frac{1}{\rho_{a}} \sum_{i=1}^{m} \int_{0}^{\infty} n_{i}(D) m_{i}(D) d D \\
& \frac{d q}{d t}=\frac{1}{\rho_{a}} \sum_{i=1}^{m} \int_{0}^{\infty} n_{i}(D) \frac{d m_{i}}{d t} d D
\end{aligned}
$$

The evaporation rate $k_{v}$ (s) can be defined such as $\frac{d n_{v}}{d t}=$ $-k_{v} n_{v}$. It can be written:

$k_{v}=\frac{1}{q} \frac{d q}{d t}=\frac{2 \sum_{i=1}^{m} \Gamma\left(\beta_{m, i}\right) \alpha_{m, i} \beta_{m, i} N_{t, i} D_{n, i}^{\left(\beta_{m, i}-1\right)} \frac{d r}{d t}\left(D_{n, i}\right)}{\sum_{i=1}^{m} \Gamma\left(2+\beta_{m, i}\right) \alpha_{m, i} N_{t, i} D_{n, i}^{\beta_{m, i}}}$

where $\frac{d r}{d t}\left(D_{n, i}\right)$ is the increase of the radius of the particle per unit of time (Pruppacher and Klett, 1997) and $\alpha_{m, i}$ and $\beta_{m, i}$ are the coefficients of the mass diameter relationship (Eq. 3). The mass diameter coefficients used are from BRAMS model: respectively $110.8 \mathrm{~kg} \mathrm{~m}^{-2.91}$ and 2.91 for pristine ice, $2.739 \times 10^{-3} \mathrm{~kg} \mathrm{~m}^{-1.74}$ and 1.74 for snow and $0.496 \mathrm{~kg} \mathrm{~m}^{-2.4}$ and 2.4 for aggregates.

\subsection{Results}

As in Sect. 3.3, the calculations are made in assuming that the total mixing ratio of $\mathrm{HNO}_{3}$ is conserved along the trajectories. Moreover the evolution of the gas mixing ratio and of the gas mixing ratio in the bulk of the ice are possible only by trapping and evaporation. In reality, this assumption is generally not true because the sedimentation and the turbulent mixing processes are not taken into account but is convenient to assess the importance of the ice uptake process (see Sect. 3.3). The important parameters are the trapping rate and the evaporation rate defined in Sects. 4.1 and 4.2. These parameters give a quantitative evaluation of the importance of the trapping/evaporation at each timestep of the simulations.
In the trapping theory, trace gases are removed from the gas phase when ice saturation ratio is larger than 1 and are released from the ice particles to the gas phase when the saturation coefficient is lower than 1. Figure 12a shows the trapping rate $k_{G}$ computed in the REF simulation as a function of time on the 7 trajectories. In this simulation the initial $\mathrm{HNO}_{3}$ gas phase mixing ratio is $100 \mathrm{pptv}$ and the bulk mixing ratio is zero. During this simulation the maximum number of adsorbed molecules per ice surface unit is generally not reached. Therefore the saturation effect of gas adsorption on the ice surface is always negligible. We observe that the trapping rate is very large (between $10^{-2} \mathrm{~s}^{-1}$ and $10^{-3} \mathrm{~s}^{-1}$ ) on the trajectories of the air parcels which are lifted rapidly by convection (purple, light blue and deep green lines) approximately between 1 and $1.4 \mathrm{~h}$ of simulation. On these trajectories $\mathrm{HNO}_{3}$ is rapidly removed from the gas phase while the air parcels are lifted by convection. On the other trajectories the trapping rate is lower with most of the values between $1 \times 10^{-5} \mathrm{~s}^{-1}$ and $7 \times 10^{-4} \mathrm{~s}^{-1}$. In this case the removal of $\mathrm{HNO}_{3}$ from the gas phase is nevertheless significant during the lifetime of the convective cloud (few hours). For larger gas phase mixing ratio of $\mathrm{HNO}_{3}$, the saturation effect of gas adsorption on the ice surface leads to a decrease of the trapping rate. Figure $12 \mathrm{~b}$ shows the trapping rate computed with an initial gas mixing ratio of $10 \mathrm{ppbv}$. During this simulation the gas mixing ratio varies between 5 and $10 \mathrm{ppbv}$ which corresponds to saturation conditions. Decreases up to a factor of 10 are observed with respect to the case without saturation effects (Fig. 12a). Figure 12c shows the trapping rate computed in the RUN1M simulation in the same conditions as for those shown in Fig. 11b. The results are consistent with those of the REF simulation. Relative large differences are nevertheless observed on particular trajectories and times. This is the case at the beginning of the high altitude trajectory (orange triangles). These differences are due to the relatively small but significant differences of the variation of the temperature on this trajectory leading to changes in water vapour deposition.

The evaporation rate $k_{v}$ computed in the REF simulation (Fig. 12d) is of the same order as the trapping rate. It is mainly a function of the water vapour saturation coefficient with respect to ice. It is also a function of the size of the ice particles. According to Eq. (18), the evaporation rates are neither dependent on the gas $\mathrm{HNO}_{3}$ concentration nor on the bulk $\mathrm{HNO}_{3}$ concentration. The evaporation rates computed in the RUN1M simulation (Fig. 12e) are also consistent with those computed in the REF simulation.

Figure 13a shows the evolution of the $\mathrm{HNO}_{3}$ gas mixing ratio computed in the REF simulation on the 7 trajectories. The total mixing ratio (gas+bulk) is conserved. In Fig. 13a the total mixing ratio is $1 \mathrm{ppbv}$. The bulk mixing ratio is assumed initially to be zero. Due to the large trapping rates at the beginning of the trajectories which are lifted by convection (purple, light blue and deep green) the removal of $\mathrm{HNO}_{3}$ from the gas phase is very large. For the other trajectories, 

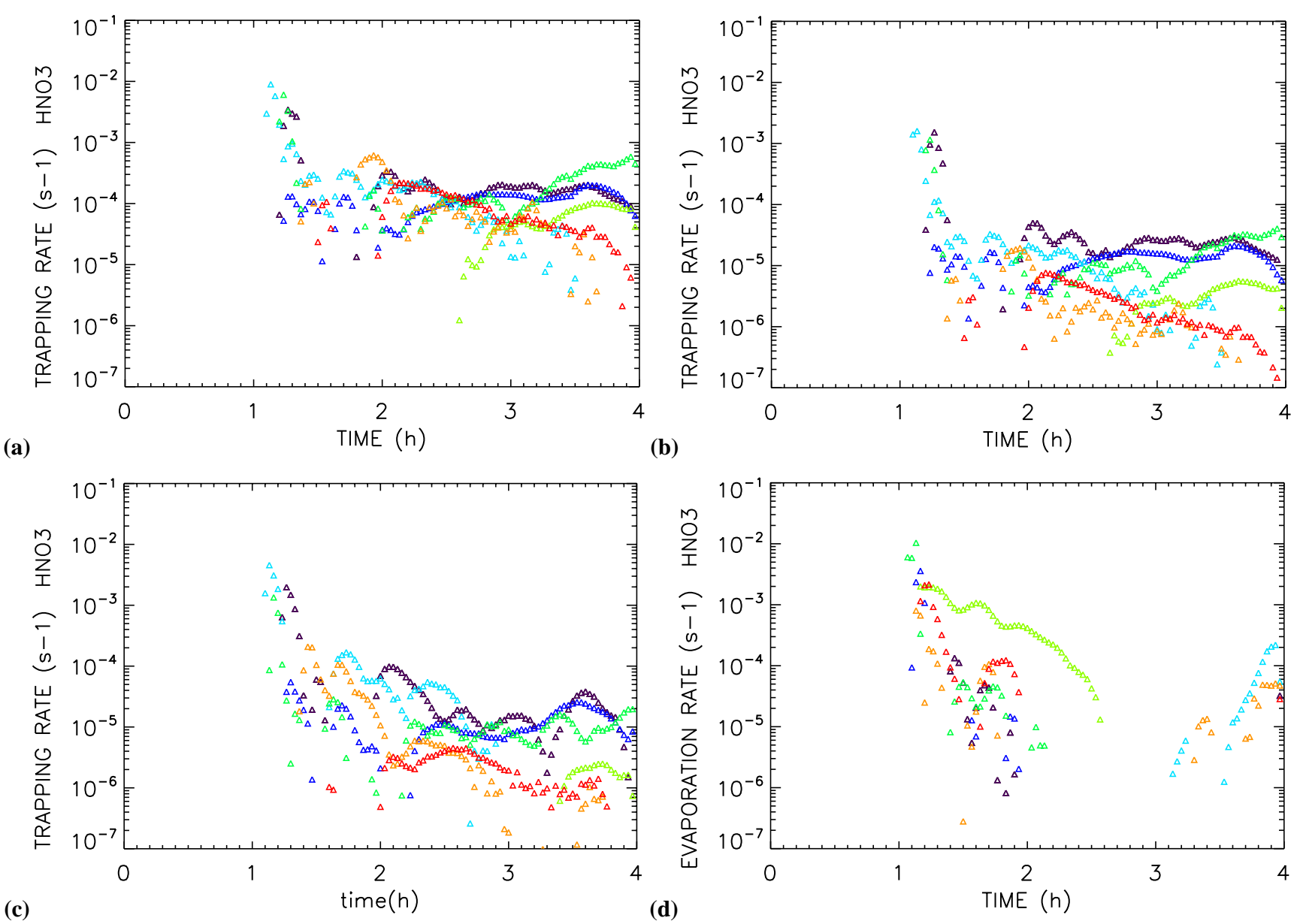

(c)

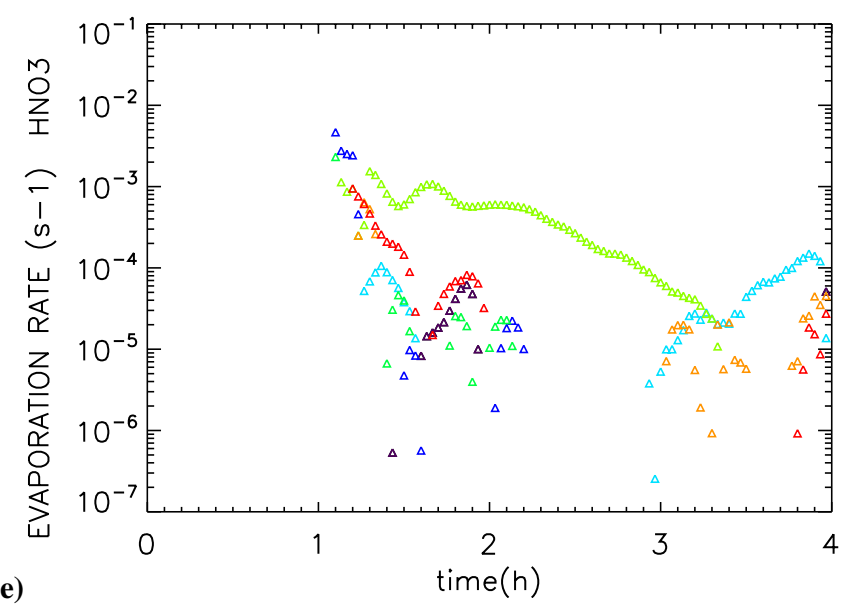

Fig. 12. Trapping and evaporation rates of $\mathrm{HNO}_{3}$ computed in the trapping theory. (a) trapping rate computed for gas $\mathrm{HNO}_{3}$ mixing ratios between 0 and 100 pptv, along trajectories of the REF simulation (b) trapping rates computed for gas $\mathrm{HNO}_{3}$ mixing ratios between 5 and 10 ppbv, along trajectories of the REF simulation (c) same as (b) along trajectories of the RUN1M simulation, (d) evaporation rate computed along trajectories of the REF simulation, (e) same as (d) for the RUN1M simulation. 

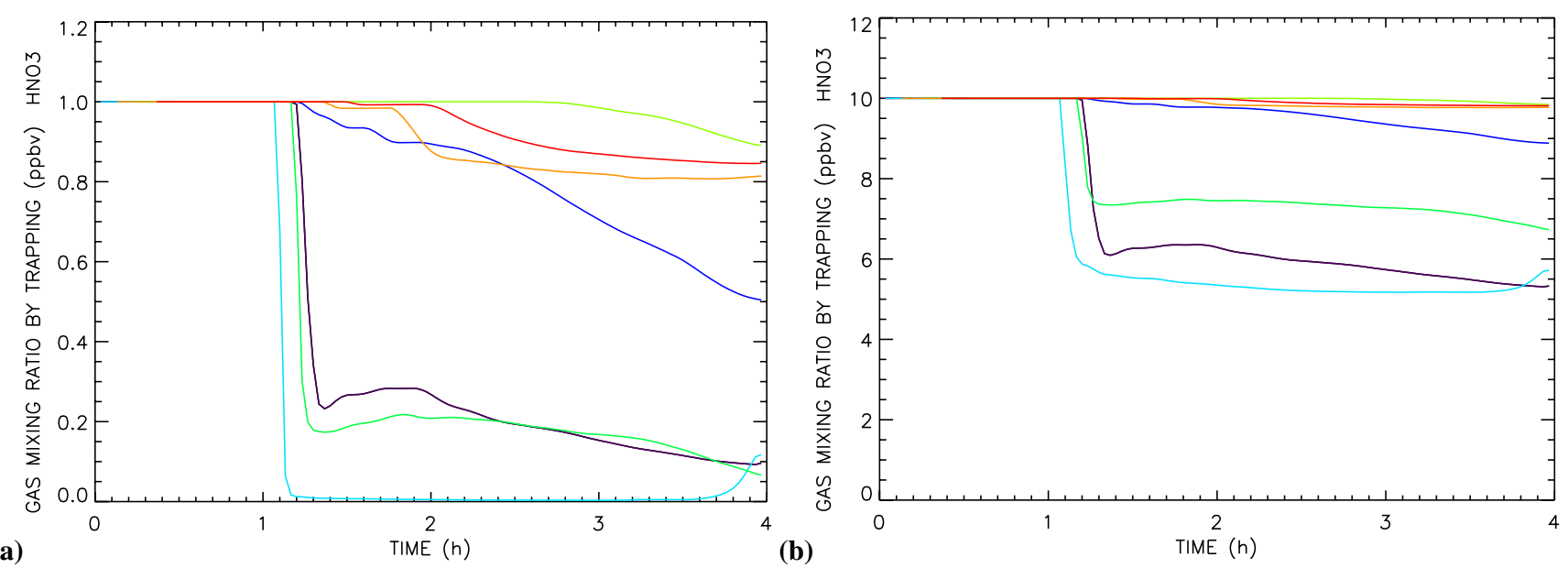

(a)

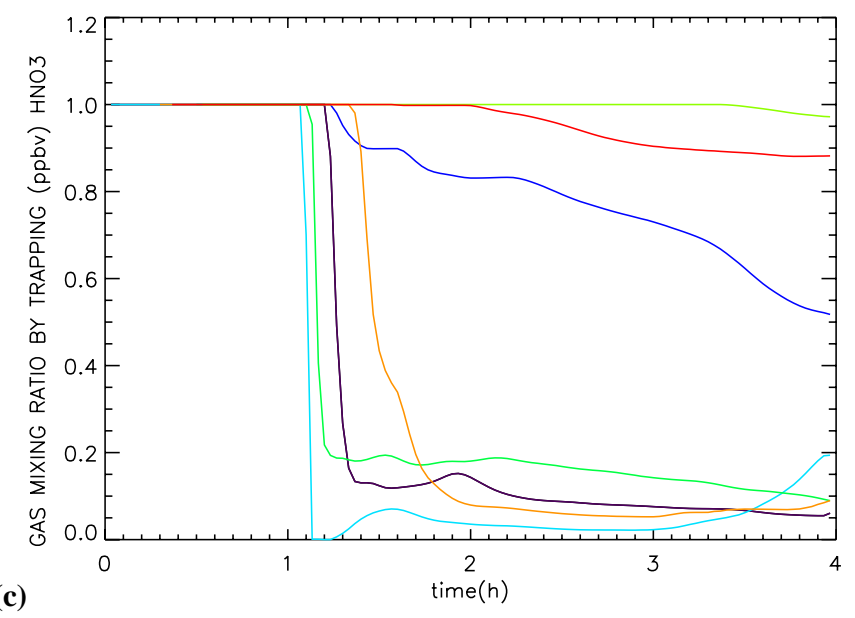

Fig. 13. Time evolution of the $\mathrm{HNO}_{3}$ gas phase mixing ratio computed in the trapping theory assuming a constant total (gas+bulk) mixing ratio. (a) Time evolution along the trajectories of the REF simulation for a total mixing ratio of 1 ppbv (b) Time evolution along the trajectories of the REF simulation for a total mixing ratio of $10 \mathrm{ppbv}$, (c) same as (a) along trajectories of the RUN1M simulation.

which stay at high altitude, it is also significant since $10 \%$ to $50 \%$ of the initial gas phase mixing ratio is removed from the gas phase at the end of the trajectories. The comparison between Figs. 10b and 13a shows that the removal of species from the gas phase computed by the Langmuir approach or by the trapping theory is on average roughly of the same order.

As discussed above the adsorption saturation effect of the ice surface can be large. This is confirmed in Fig. 13b which shows the evolutions of the $\mathrm{HNO}_{3}$ gas phase mixing ratio assuming a total mixing ratio of $10 \mathrm{ppbv}$ on the 7 trajectories. In this case the removal is $<50 \%$ of the initial gas mixing ratio for all trajectories. It is negligible for three of the trajectories (light green, red and orange). This is because for these trajectories the water vapour deposition and evaporation is low and adsorption saturation effect is large.

Figure $13 \mathrm{c}$ shows the results for a total mixing ratio of $1 \mathrm{ppbv}$ in the RUN1M simulation. The results are consistent with those of the REF simulation (Fig. 13a) except for the highest altitude trajectory (orange line). This is due to the higher trapping rate computed in the RUN1M simulation as already discussed above.

\section{Impact of graupel in the Langmuir and the trapping approaches}

The definition of the graupel ice category in the microphysics parametrization used here is from Walko et al. (1995): "Graupel is an intermediate density hydrometor. It is assumed to be spherical in shape, and to be fomed by moderate to heavy riming and/or partial melting of pristine ice, snow and aggregates. Graupel is allowed to carry up to only a low percentage of liquid". It does not strictly enter therefore in our definition of "dry ice" of concern in this paper. But at temperatures lower than $235 \mathrm{~K}$, the percentage of liquid is likely to be very low and neglecting graupel could lead to an underestimation of the trace gas uptake in both the Langmuir and the trapping approaches. Calculations have been 
repeated but taking into account the graupel ice category. Graupel is present at the very beginning of the 7 trajectories studied in this paper with mixing ratio values close to aggregates. But graupel mixing ratio vanishes rapidly with time due to sedimentation.. Along the 7 trajectories studied in this paper the impact of graupel is less than $0.5 \%$ for the mean mixing ratio in the gas phase compared to the REF simulation in the Langmuir approach (Table 1). It is $3 \%$ for $\mathrm{HNO}_{3}$ if only the part of the trajectories where graupel is present is taken into account. It is $1 \%$ for $\mathrm{HCl}$ and less than $0.25 \%$ for the other trace gases. Because of its intermediate density and its characteristic diameter is larger than the characteristic diameter of aggregates, snow and pristine ice, the surface area of graupel is very small compared with aggregates, snow and pristine ice for the same mixing ratio. This explains the low impact of graupel on the trace gas uptake in the Langmuir approach.

In the trapping theory the mean value on the 7 trajectories of the trapping rate defined in Sect. 4.1 and shown in Fig. 12a, is increased by only $2 \%$. It is increased by $4 \%$ if only the part of the trajectories where graupel is present is taken into account.

The impact of graupel on the trace gas uptake in the Langmuir approach as well as in the trapping theory can therefore be neglected.

\section{Discussion and conclusion}

The overall objective of this paper is to assess the importance of the reversible ice uptake process for various gas species in the cold part of deep convective clouds $(T<235 \mathrm{~K})$. This is done to prepare the incorporation of this process in a 3-D limited area cloud model. To this end an idealized convective cloud is simulated with the 3-D cloud resolving model BRAMS and ice uptake is studied on 7 air parcels trajectories representative of the different ice histories inside the cloud and within its environment. A reference simulation using a two-moment microphysical scheme (Meyers et al., 1997) and a sensitivity test using a one-moment scheme (Walko and al., 1995) are done. The Langmuir approach and the trapping theory are both studied.

The Langmuir approach is used for 11 species for which the parameters are assessed by the IUPAC Subcommittee on Gas Kinetic Data Evaluation (Crowley et al., 2010 and http://www.iupac-kinetic.ch.cam.ac.uk). Due to the balance between the adsorption and desorption processes, an instantaneous equilibrium is assumed between the gas phase mixing ratio and the surface mixing ratio of each species. This assumption is justified since the time step of the calculations $(120 \mathrm{~s})$ is larger than the time needed to reach the equilibrium on average on all the trajectories ( $3 \mathrm{~s}$ to $45 \mathrm{~s}$ ). In both simulations the surface mixing ratio is found to be negligible along all trajectories for PAN, $\mathrm{HCHO}, \mathrm{CH}_{3} \mathrm{COCH}_{3}$ and $\mathrm{CH}_{3} \mathrm{OH}$, and small for $\mathrm{C}_{2} \mathrm{H}_{5} \mathrm{OH}$ and $\mathrm{C}_{3} \mathrm{H}_{7} \mathrm{OH}$. On average over all the trajectories the surface mixing ratio is significant compared with the total mixing ratio for $\mathrm{HCOOH}(6 \%)$, $\mathrm{CH}_{3} \mathrm{COOH}(17 \%), \mathrm{HCl}(50 \%)$ and $\mathrm{HNO}_{3}(80 \%)$. For these species the surface mixing ratio can be very large in some particular cases $36 \%, 67 \%, 91 \%$ and $99 \%$ respectively. For $\mathrm{H}_{2} \mathrm{O}_{2}$ the surface mixing ratio is negligible when using the published data of Clegg and Abbatt, 2001, but is significant (8\% on average with a maximum of $36 \%$ ) if the partition coefficient derived from new laboratory studies (Pouvesle et al., 2010) is used. The effect of saturation the ice surface is observed for mixing ratios of $\mathrm{HNO}_{3}$ and $\mathrm{HCl}$ larger than 1 ppbv. This saturation effect leads to an increase of the gas phase mixing ratio relative to the total (gas+ice) mixing ratio up to a factor 4 for a $\mathrm{HNO}_{3}$ total mixing ratio of $10 \mathrm{ppbv}$. The saturation effect is very low for the other trace gases. Nevertheless, if the saturation effect occurs for $\mathrm{HNO}_{3}$ or $\mathrm{HCl}$, an impact must be observed on the surface mixing ratio of the other trace gases due to competitive adsorptions. This impact will have to be taken into account in a 3-D model. A simulation called RUN1M was also run with a single moment microphysical scheme instead of the two-moment scheme to test the sensitivity of the results to the ice microphysics. Gas phase mixing ratios in the RUN1M simulation have been found to be consistent with the results obtained in the REF simulation but are usually lower because the RUN1M simulation provides larger dry ice mixing ratio along the trajectories than the REF simulation The one-moment microphysical scheme can be therefore a good approximation in a 3-D cloud model if necessary to reduce the computation time.

The trapping theory developed by Karcher and Basko (2004) and by Karcher et al. (2009) for $\mathrm{HNO}_{3}$ has been used. The trapping rate of $\mathrm{HNO}_{3}$ has been shown to be very large $\left(10^{-3}\right.$ to $\left.10^{-2} \mathrm{~s}^{-1}\right)$ on trajectories of air parcels which are rapidly uplifted by convection, leading to fast removal of $\mathrm{HNO}_{3}$ from the gas phase. On the other trajectories the rate is lower $\left(10^{-5}\right.$ to $\left.7 \times 10^{-4} \mathrm{~s}^{-1}\right)$ but still leads to significant $\mathrm{HNO}_{3}$ removal from the gas phase for the lifetime of the convective cloud. The saturation effect on the ice surface is observed on the trapping rate which is reduced by a factor 10 when $\mathrm{HNO}_{3}$ mixing ratio in the gas phase increases from $100 \mathrm{pptv}$ to $10 \mathrm{ppbv}$. An evaporation rate was also defined assuming a uniform concentration of the species in the bulk of the ice particles. It is of the same order as the trapping rate. The $\mathrm{HNO}_{3}$ removal computed by the trapping theory is of the same order as in the Langmuir approach for $\mathrm{HNO}_{3}$. Trapping could therefore be important for the other species $\mathrm{HCl}, \mathrm{H}_{2} \mathrm{O}_{2}, \mathrm{CH}_{3} \mathrm{C}(\mathrm{O}) \mathrm{OH}$ and $\mathrm{HC}(\mathrm{O}) \mathrm{OH}$ for which the Langmuir approach removal is significant, though the lack of confirmatory data from either the laboratory or field experiments precludes a definite conclusion at this stage.

For both Langmuir and trapping calculations, only dry ice species have been considered for the calculation, meaning pristine ice, snow and aggregates. Graupels possibly carry only very small amount of liquid water at the atmospheric temperature considered $(<235 \mathrm{~K})$. If was checked a 
posteriori that the contribution of graupel to ice uptake was small to negligible because of their efficient sedimentation and their small surfaces compared to pristine ice, snow and aggregates for a given mixing ratio.

In a 3-D cloud model, all species for which the uptake is significant will be treated using the Langmuir theory, except $\mathrm{HNO}_{3}$ for which the trapping theory exists. We will introduce ice surface mixing ratio variables for $\mathrm{HCl}, \mathrm{H}_{2} \mathrm{O}_{2}$, $\mathrm{CH}_{3} \mathrm{C}(\mathrm{O}) \mathrm{OH}$ and $\mathrm{HC}(\mathrm{O}) \mathrm{OH}$. Other species such as $\mathrm{HONO}$ and $\mathrm{HO}_{2} \mathrm{NO}_{2}$ could be added later once their partition coefficient is assessed by IUPAC. The time evolution of $\mathrm{HCl}$, $\mathrm{H}_{2} \mathrm{O}_{2}, \mathrm{CH}_{3} \mathrm{C}(\mathrm{O}) \mathrm{OH}$ and $\mathrm{HC}(\mathrm{O}) \mathrm{OH}$ species will be computed by the Langmuir approach assuming the equilibrium between adsorption and desorption. This will limit the time resolution of the calculations since the equilibrium is justified only if the time required to reach the equilibrium is lower than the timestep. In the cases studied in the present paper the time to reach the equilibrium was found for these species to be between $3 \mathrm{~s}$ and $20 \mathrm{~s}$ on average but it can be larger in some particular cases. For instance, a maximum time of $140 \mathrm{~s}$ for $\mathrm{CH}_{3} \mathrm{C}(\mathrm{O}) \mathrm{OH}$ was computed.

For $\mathrm{HNO}_{3}$ the Langmuir and the trapping approaches can be applied. On one hand, the Langmuir theory assumes that the ice surface is in a steady state and in principle only applies to this case. On the other hand, the trapping approach is valid when water deposition on ice is significant. At the present stage of the development of the trapping theory the location of the trapped species and in particular the number of species on the ice surface is not yet determined. Knowledge of not only the gas-to-ice partitioning but also the ice surface mixing ratio of absorbed trace gases is needed because the reactive interaction of other species with the ice surface can depend on the surface composition. In the adsorption limit of the trapping theory, the surface mixing ratio derived by the Langmuir approach can be nevertheless assumed. It seems reasonable to use this approach in the case when the trapping rate or the evaporation rate is low relative to the rate constant to reach the Langmuir equilibrium. The trapping rate and the evaporation rate for $\mathrm{HNO}_{3}$ are between $10^{-6} \mathrm{~s}^{-1}$ and $10^{-3} \mathrm{~s}^{-1}$ most of the time (Fig. 12a, b and d) while the rate constant to reach the Langmuir equilibrium is on average on all the trajectories between $10^{-1} \mathrm{~s}^{-1}$ and $2 \times 10^{-2} \mathrm{~s}^{-1}$ with a minimum of $4 \times 10^{-3} \mathrm{~s}^{-1}$. Therefore we will introduce in the 3-D cloud model a variable for the bulk mixing ratio and also a variable for the ice surface mixing ratio. In the cases of low trapping or low evaporation rates the evolution of the bulk mixing ratio of $\mathrm{HNO}_{3}$ will use the trapping and evaporation as proposed by Kärcher et al. (2009) and the evolution of the surface mixing ratio will use the Langmuir equilibrium.

Acknowledgements. This work was supported by the European integrated project SCOUT-O3 (GOCE-CT-2004-505390) and by the program LEFE/INSU in France (projects UTLS-tropicale and Tropopause 2009). BRAMS is a free software developed by CPTEC/INPE and distributed under the CC-GNU-GPL license. The radiosounding data used in this study comes from the TROCCIBRAS database. We acknowledge B. Kärcher for fruitful discussions on the trapping theory. We also acknowledge R. Joussot, M. Francis and J. B. Renard for their help.

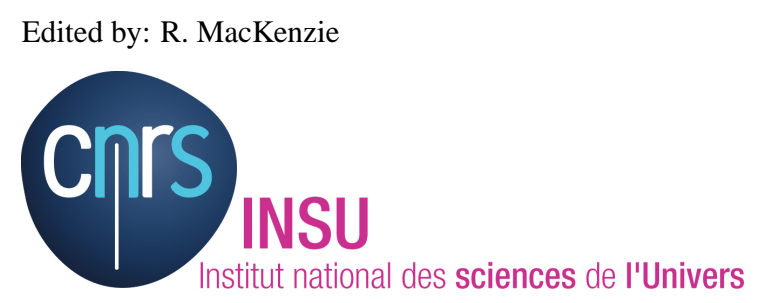

The publication of this article is financed by CNRS-INSU.

\section{References}

Abbatt, J. P.D.: Interaction of $\mathrm{HNO}_{3}$ with water-ice surfaces at temperatures of the free troposphere, Geophys. Res. Lett., 24, 14791482, 1997.

Audiffren, N., Renard, M., Buisson, E., and Chamerliac, N.: Deviations from the Henry's law equilibrium during cloud events: a numerical approach of the mass transfer between phases and its specific numerical effects, Atmos. Res., 49, 139-161, 1998.

Bartels, T., Eichler, B., Zimmermann, P., Gggeler, H. W., and Ammann, M.: The adsorption of nitrogen oxides on crystalline ice, Atmos. Chem. Phys., 2, 235-247, doi:10.5194/acp-2-235-2002, 2002.

Bartels-Rausch T., Guimbaud, C., Gäggeler, H. W., and Ammann, M.: The partitioning of acetone to different types of ice and snow between 198 and 223 K, Geophys. Res. Lett., 31, L16110, doi:10.1029/2004GL020070, 2004 (erratum in Geophys. Res. Lett., 31, L23106, doi:10.1029/2004GL021838., 2004).

Barth, M. C., Rasch, P. J., Kiehl, J. T. Benkovitz, C. M., and Schwartz, S. E.: Sulfur chemistry in the National Center for Atmospheric Research Community Climate Model: Description, evaluation, features, and sensitivity to aqueous chemistry, J. Geophys. Res., 105(D1), 1387-1415, 2000.

Barth, M. C., Stuart, A. L., and Skamarock, W. C.: Numerical simulations of the 10 July 1996, Stratospheric-Troposheric Experiment: Radiation, Aerosols, and ozone (STERAO)-Deep convection experiment storm: redistribution of soluble tracers, J. Geophys. Res., 106(D12), 12381-12400, 2001.

Baumgardner, D., Jonsson, H., Dawson, W., O'Connor, D., and Newton, R.: The cloud, aerosol and precipitation spectrometer: a new instrument for cloud investigations, Atmos. Res., 59-60, 251-264, 2001.

Chu, L., Diao, G., and Chu, L.T.: Heterogeneous interaction and reaction of HONO on ice films between 173 and $230 \mathrm{~K}$, J. Phys. Chem. A., 104, 3150-3158, 2000.

Clegg, S. M. and Abbatt, J. P. D., Uptake of gas-phase $\mathrm{SO}_{2}$ and $\mathrm{H}_{2} \mathrm{O}_{2}$ by ice surface: dependence on partial pressure, temperature and surface acidity, J. Phys. Chem., 105, 6630-6636, 2001.

Cohan, D. S., Schultz, M. G., Jacob, D. J., Heikes, B. G., and Blake, D. R.: Concective injection and photochemical decay of peroxides in the tropical upper troposphere: Methyl iodide as a tracer of marine convection, J. Geophys. Res., 104, 5717-5724, 1999. 
Collins, W. J., Stevenson, D. S., Johnson, C. E., and Derwent, R. G.: Role of convection in determining the budget of odd hydrogen in the upper troposphere, J. Geophys. Res., 104, 26927-26941, 1999.

Cox, R. A., Fernandez, M. A., Symington, A., Ullerstam, M., and Abbatt, J. P. D.: A kinetic model for uptake of $\mathrm{HNO}_{3}$ and $\mathrm{HCl}$ on ice in a coated-wall flow system, Phys. Chem. Chem. Phys., 7, 3434, doi:10.1039/b506683b, 2005.

Crowley, J. N., Ammann, M., Cox, R. A., Hynes, R. G., Jenkin, M. E., Mellouki, A., Rossi, M. J., Troe, J., and Wallington, T. J.: Evaluated kinetic and photochemical data for atmospheric chemistry: Volume V heterogeneous reactions on solid substrates, Atmos. Chem. Phys. Discuss., 10, 5233-5564, doi:10.5194/acpd10-5233-2010, 2010.

Crutzen, P. J. and Laurence M. G., The impact of precipitation scavenging on the transport of trace gases: A 3-dimensional model sensitivity study, J. Atmos. Chem., 37, 81-112, 2000.

Danielsen, E. F.: In situ evidence of rapid vertical, irreversible transport of lower tropopspheric air into the lower tropical stratosphere by convective cloud turrets and by larger-scale upwelling in tropical cyclones, J. Geophys. Res., 98(D5), 8665-8681, 1993.

Dickerson, R. R., Huffman, G. J., Luke, W. T., Nunnermacker, L.J., Pickering, K. E., Leslie, A. C. D., Lindsey, C. G., Slinn, W. G. N., Kelly, T.J., Daum, P. H., Delany, A.C., Greenberg, J. P., Zimmerman, P. R., Boatman, J. F., Ray, J. D., and Stedman, D. H.: Thunderstorms: an important mechanism in the transport of air pollutants, Science, 235, 460-465, 1987.

Diehl, K., Mitra, S. K., and Pruppacher, H. R.: A laboratory study on the uptake of $\mathrm{HNO}_{3}$ and $\mathrm{HCl}$ vapor by snow crystals and ice spheres at temperatute between 0 and $-40 \circ \mathrm{C}$, Atmos. Environ., 29A, 975-981, 1995.

Dominé, F. and Rey-Hanot, L.: Adsorption isotherms of acetone on ice between 193 and 213K, Geophys. Res. Lett., 29(18), 1873, doi:10.1029/2002GL015078, 2002.

Fischer, H., de Reus, M., Traub, M., Williams, J., Lelieveld, J., de Gouw, J., Warneke, C., Schlager, H., Minikin, A., Scheele, R., and Siegmund, P.: Deep convective injection of boundary layer air into the lowermost stratosphere at midlatitudes, Atmos. Chem. Phys., 3, 739-745, doi:10.5194/acp-3-739-2003, 2003.

Freitas S. R., Silva Dias, M. A. F., Silva Dias, P. L., Longo, K. M., Artaxo, P., Andreae, M. O., and Fischer, H.: A convective kinematic trajectory technique for low-resolution atmospheric models, J. Geophys. Res., 105, 24375-24386, 2000.

Freitas, S. R., Longo, K. M., Silva Dias, M. A. F., Chatfield, R., Silva Dias, P., Artaxo, P., Andreae, M. O., Grell, G., Rodrigues, L. F., Fazenda, A., and Panetta, J.: The Coupled Aerosol and Tracer Transport model to the Brazilian developments on the Regional Atmospheric Modeling System (CATT-BRAMS) - Part 1: Model description and evaluation, Atmos. Chem. Phys., 9, 28432861, doi:10.5194/acp-9-2843-2009, 2009.

Gerber, H., Takano, Y., Garrett, T. J., and Hobbs, P. V.: Nephelometer measurements of the asymmetry parameter, volume extinction coefficient, and backscatter ratio in arctic clouds, J. Atmos. Sci., 57, 3021-3034, 2000.

Grosvenor, D. P., Choularton, T. W., Coe, H., and Held, G.: A study of the effect of overshooting deep convection on the water content of the TTL and lower stratosphere from Cloud Resolving Model simulations, Atmos. Chem. Phys., 7, 4977-5002, doi:10.5194/acp-7-4977-2007, 2007.
Harrington, J. Y.: The effects of radiative and microphysical processes on simulated warm and transition season Arctic stratus, PhD Diss., Atmospheric Science Paper No. 637, Colorado State University, Department of Atmospheric Science, Fort Collins, CO 80523, 289 pp., 1997.

Held, G., Pommereau, J.-P., and Schumann, U.: TroCCiBras and its partner projects HIBISCUS and TROCCINOX: The 2004 Field Campaign in the State of São Paulo, Opt.Pura. Apl., 41(2), 207216, 2008.

Hobbs, P. V., 1974, Ice physics, Oxford University Press, 837 pp., 1974.

Hudson, P. K., Shilling, J. E., Tolbert, M. A., and Toon., O. B.: Uptake of Nitric Acid on Ice at Tropospheric Temperatures: Implications for Cirrus Clouds., J. Phys. Chem. A, 106, 9874-9882, 2002.

Huffman, W. A. and Snider, J. R.: Ice-oxyhydrocarbon interactions in the troposphere, J. Geophys. Res., 109, D01302, doi:10.1029/2003JD003778, 2004.

Hynes, R. G., Fernandez, M. A., and Cox, R. A.: Uptake of $\mathrm{HNO}_{3}$ on water-ice and coadsorption of $\mathrm{HNO}_{3}$ and $\mathrm{HCl}$ in the temperature range 210-235 K, J. Geophys. Res., 107(D24), 4797, doi:10.1029/2001JD001557, 2002.

Kärcher, B. and Basko, M. M.: Trapping of trace gases in growing ice crystals, J. Geophys. Res., 109, D22204, doi:10.1029/2004JD005254, 2004.

Kärcher, B., Abbatt, J. P. D., Cox, R. A., Popp, P. J., and Voigt, C.: Trapping of trace gases by growing ice surfaces including surface-saturated adsorption, J. Geophys. Res., 114, D13306, doi:10.1029/2009JD011857, 2009

Kerbrat, M., Le Calvé, S., and Mirabel, P.: Uptake measurements of ethanol on ice surfaces and on supercooled aqueous solutions doped with nitric acid between 213 and 243 K., J. Phys. Chem. A, 111, 925-931, 2007.

Marécal, V., Rivire, E. D., Held, G., Cautenet, S., and Freitas, S.: Modelling study of the impact of deep convection on the utls air composition - Part I: Analysis of ozone precursors, Atmos. Chem. Phys., 6, 1567-1584, doi:10.5194/acp-6-1567-2006, 2006.

Mari, C., Jacob, D. J., and Bechtold, P.: Transport and scavenging of soluble gases in a deep convective cloud, J. Geophys. Res., 105(D17), 22255-22268, doi:10.1029/2000JD900211, 2000.

Meier, A. and Hendricks, J.: Model studies on the sensitivity of upper trpospheric chemistry to heterogeneous uptake of $\mathrm{HNO}_{3}$ on cirrus ice particles, J. Geophys. Res., 107, 4696, doi:10.1029/2001JD000735, 2002.

Mellor, G. L. and Yamada, T.: Development of a turbulence closure model for geophysical fluid problems, Rev. Geophys. Space Phys., 20, 851-875, 1982.

Meyers, M. P., Walko, R. L., Harrington, J. Y., and Cotton, W. R.: New RAMS cloud microphysics parameterization. Part II: The two-moment scheme, Atmos. Res., 45, 3-39, 1997.

Peybernès, N., Le Calvé, S., Mirabel, P., Picaud S., and Hoang, P. N. M.: Experimental and theoretical adsorption study of ethanol on ice surfaces, J. Phys. Chem. B, 108, 17425-17432, 2004.

Popp, P. J., Gao, R. S., Marcy, T. P., et al.: Nitric acid uptake on subtropical cirrus cloud particles, J. Geophys. Res., 109, D06302, doi:10.1029/2003JD004255, 2004.

Prather, M. J. and Jacob, D. J.: A persistent imbalance in $\mathrm{HO}_{\mathrm{x}}$ and $\mathrm{NO}_{\mathrm{x}}$ photochemistry of the upper troposphere driven by deep 
tropical convection, Geophys. Res. Lett., 24, 3189-3192, 1997.

Pruppacher, H. R. and J. D. Klett: Microphysics of clouds and precipitation, Kluwer Acad., Norwell, Mass, 1997.

Rivière, E. D., Marécal, V., Larsen, N., and Cautenet, S.: Modelling study of the impact of deep convection on the UTLS air composition - Part 2: Ozone budget in the TTL, Atmos. Chem. Phys., 6, 1585-1598, doi:10.5194/acp-6-1585-2006, 2006.

Sander, R.: Compilation of Henry's law constants for inorganic and organic species of potential importance in environmental chemistry (Version 3), http://www.mpch-mainz.mpg.de/\$ $\backslash$ sim\$sander/res/henry.html, 1999.

Sokolov, O., and Abbatt, J. P. D.: Adsorption to ice of nalcohols (ethanol to 1-hexanol), acetic acid and hexanal, J. Phys. Chem. A, 106, 775-782, 2002.

Tabazadeh, A. and Turco, R.: A model for heterogeneous chemical processes on the surfaces of ice and nitric acid trihydrate particles, J. Geophy. Res., 98(D7), 12727-12740, 1993.

Tabazadeh, A., Toon, O. B., and Jensen, E. J.: A surface chemistry model for nonreactive trace gas adsorption on ice: Implications for nitric acid scavenging by cirrus, Geophys. Res. Lett., 26(14), 2211-2214, 1999.

Ullerstam, M. and Abbatt, J. P. D.: Burial of gas-phase $\mathrm{HNO}_{3}$ by growing ice surfaces under troposperic conditions, Phys. Chem. Chem. Phys., 7, 3596-3600, 2005.

Voigt, C., Kärcher, B., Schlager, H., Schiller, C., Krmer, M., de Reus, M., Vössing, H., Borrmann, S., and Mitev, V.: In-situ observations and modeling of small nitric acid-containing ice crystals, Atmos. Chem. Phys., 7, 3373-3383, doi:10.5194/acp7-3373-2007, 2007.

von Hessberg, P., Pouvesle, N., Winkler, A. K., Schuster, G., and Crowley, J. N.: Interaction of formic and acetic acid with ice surfaces between 187 and $227 \mathrm{~K}$. Investigation of single species and competitive adsorption, Phys. Chem. Chem. Phys., 10, 23452355, doi:10.1039/b800831k, 2008. von Kuhlmann, R., Lawrence, M. G., Crutzen, P. J., and Rash, P. J.: A model for studies of tropospheric ozone and non-methane hydrocarbons: Model description and ozone results, J. Geophys. Res., 108, 4294, doi:10.1029/2002JD002893, 2003.

von Kuhlmann, R. and Lawrence, M. G.: The impact of ice uptake of nitric acid on atmospheric chemistry, Atmos. Chem. Phys., 6, 225-235, doi:10.5194/acp-6-225-2006, 2006.

Walko, R. L., Cotton, W. R., Meyers, M. P., and Harrington, J. Y.: New RAMS cloud microphysics parameterization. Part I: the single-moment scheme, Atmos. Res., 38, 29-62, 1995.

Wang, C., Crutzen, P. J., Ramanathan, V., and Williams, S. F.: The role of a deep convective storm over the tropical Pacific Ocean in the redistribution of atmospheric chemical species, J. Geophys. Res., 100(D6), 11509-11516, 1995.

Wang, C.: A modelling study of the response of tropical deep convection to the increase of cloud condensation nuclei concentration: 2. Radiation and tropospheric chemistry, J. Geophys. Res., 110, D22204, doi:10.1029/2005JD005829, 2005.

Warneck, P.: Chemistry of the natural atmosphere, International geophysics Series, Vol. 71, Academic press, 927 pp, 2000.

Winkler, A.K., Holmes, N.S., and Crowley, J.N., Interaction of acetone, formaldehyde and methanol with ice surfaces between 198 and 223 K, Phys. Chem. Chem. Phys., 4, 5270-5275, 2002.

Wyser, K. and Yang, P.: Average ice crystal size and bulk short wave single-scattering properties of cirrus clouds, Atmos. Res., 49, 315-335, 1998.

Yin, Y., Carslaw, K. S., and Parker, D. J.: Redistribution of trace gases by convective clouds - mixed-phase processes, Atmos. Chem. Phys., 2, 293-306, doi:10.5194/acp-2-293-2002, 2002.

Zondlo, M. A., Barone, S. B., and Tolbert, M. A.: Uptake of $\mathrm{HNO}_{3}$ on ice under upper troposheric conditions, Geophys. Res. Lett, 24, 1391-1394, 1997. 